\title{
FACHADA DE LA UNIVERSIDAD DE SALAMANCA Y PATIO DE LAS ESCUELAS MENORES
}

\section{Por Vicente Martin Hernández}

\section{Antecedentes históricos}

El renacimiento que se produjo en toda Europa durante el siglo XIII, en el campo de los estudios, determinó el auge de las instituciones de enseñanza, monásticas y episcopales, que entonces existían. Aquellas que merecieron el favor de los reyes y fueron sometidas a la autoridad de los papas se transformaron en universidades adquiriendo carácter internacional, siendo la de Salamanca una de las primeras en alcanzar dicho rango.

La Universidad Salmantina -que durante mucho tiempo se llamó El Estudio-, inició sus actividades en el seno de la catedral vieja y estuvo bajo su jurisdicción hasta el siglo xiv. La organización y privilegios que recibió de los monarcas y del papado contribuyeron poderosamente a su desarrollo, favorecido también por las corrientes culturales de la baja Edad Media. Durante los siglos xIII, xiv y XV, a pesar cle la decadencia de otras actividades sociales que sufrió el reino y de las vicisitudes que padeció la ciudad, la Universidad no solamente sobrevivió sino que aumentó considerablemente en importancia, adquiriendo gran fama dentro y fuera de España, lo que motivó que acudieran a ella numerosas gentes de otros países y reinos.

La Universidad Salmantina tuvo desde su origen carácter real y pontificio por la doble protección de que gozó. Se atribuye al rey Alfonso IX de León el traslado a Salamanca, a principios del siglo XIII (1218), de las Escuelas de Palencia, cuya actividad se había debilitado; San Fernando la consolidó en 1243 (fecha que se considera la de su fundación), y Alfonso $\mathrm{X}$ la reglamentó y amplió en 1254, dotándola de nuevas cátedras. El papa Alejandro IV la titula -junto con las de Bolonia, Paris y Oxford-, una de las cuatro "lumbreras del mundo", siendo al parecer, este pontífice el que concedió a la Universidad la categoría de Estudio General, privilegio otorgado también a las otras universidades mencionadas. En 1298, los papas la sometieron a su inmediata jurisdicción, dando a los estudios el carácter de universales. Merced a sus poderosos patrocinadores pudo la Universidad superar la dificil cri- 
sis que atravesó en el siglo xIv. En el xv, recibió nuevos y vigorosos impulsos, gracias al cardenal don Pedro de Luna (el futuro Benedicto XIII), quien la dotó de constituciones, y a los favores que recibió de los reyes Juan II, Enrique IV y del papa Martín V. Al finalizar el siglo, los Reyes Católicos contribuyeron de manera decisiva al auge de la Universidad y a la transformación del edificio universitario.

\section{El edificio universitario}

$\mathrm{Su}$ historia comienza a principios del siglo $\mathrm{xv}$, cuando se proyectó $e$ inició la construcción de un edificio en el que pudieran desarrollarse los estudios, y proporcionarse el ámbito propicio para que la organización corporativa y gremial de maestros y escolares la Universitas, ejerciera con mayor independencia y eficacia sus funciones.

Con la construcción del edificio termina el periodo embrionario de la vida del Estudio y comienza la gloriosa, fecunda, compleja y agitada historia de la Universidad. La arquitectura, al dar corporeidad física a la institución docente, acrecentó su personalidad y la autonomía de las ciencias y doctrinas, con to cual el carácter contemplativo y pasivo, que hasta entonces había dominado, se transformó en activo y dinámico. Al finalizar el siglo xv, la Universidad se convirtió en cerebro del reino y en alma y corazón de Salamanca, determinando su desarrollo social, artístico y monumental. Su fama e importancia, no sólo académica, sino también política, contribuyó a partir de entonces a la creación de numerosos colegios, conventos, monasterios, hospitales, etcétera, que aumen. taron extraordinariamente el prestigio, población y riquezas de la ciudad.

Las obras se comenzaron en 1415 y el proceso de construcción se prolongó durante más de medio siglo. El conjunto debió quedar completado hacia 1479 , fecha en que se terminó de construir, sobre la segunda capilla, la librería vieja.

El primitivo edificio tenía como núcleo central, a la manera monástica, el patio o claustro, en torno del cual estaban las aulas o "generales"; tenían éstas techos de madera -obra probable de artifices moriscos-, y muros desnudos, cuya severidad podemos percibir todavia en los que aún se conservan. En medio del ala oriental se erigió la primera capilla, que fue bendecida en 1429 (su artesano morisco es el que cubre el zaguán que da acceso al atrio de la catedral). El claustro primitivo, constituye la planta baja del actual, formado por arcos de medio punto y pilares en arista viva, sin modulación ni adorno alguno; su gran sencillez está atenuada en las galerías por los galanos artesonados que las cubren. 
Poseía la primitiva fábrica una sola portada situada detrás de la actual y al paño con el muro. Aunque no existe memoria de ella, podemos suponer, a juzgar por la sobriedad del edificio, que no tuvo gran importancia arquitectónica ni riqueza ornamental. Debió tener una sola puerta, con arco de medio punto de grandes dovelas -semejante a las de otros edificios civiles salmantinos de aquella época-, enmarcada con alfiz y rematada con escudo o imagen religiosa, en hornacina o nicho. (El arco es, al parecer, el que aún se conserva y separa los dos tramos del zaguán actual.)

El conjunto del edificio (salvo la ornamentación de los artesonados) era de gran austeridad, explicable por su carácter civil y el aspecto monástico que presidió su concepción $y$, en parte, por las vicisitudes históricas que afectaron al reino, y las violencias que padeció la ciudad durante aquel siglo, las cuales debieron, en ocasiones, limitar o mermar las rentas y donaciones destinadas a la obra, obligando a hacer economías en lo ornamental y superfluo. La sencillez del exterior era mayor aún que la del interior. Hasta que fue construida la nave de la segunda capilla -que rebasó el perímetro primitivo y rompió la unidad de altura-, el edificio era de planta casi rectangular y altura uniforme; los muros exteriores, formados en gran parte de tosca mamposterfa, tenian escasas y angostas ventanas, y de trecho en trecho sobresalían sólidos contrafuertes. Su ruda apariencia exterior (todavía visible en la fachada norte, contigua a la actual Facultad de Derecho) acentuaba su carácter introvertido. Esta imagen no está sin duda, de completo acuerdo con el juicio que mereció a un viajero alemán, llamado Münzer, que visitó Salamanca entre los años 1494 y 1495, quien refiriéndose a esta obra decía: "Hay en Salamanca un colegio de bella apariencia recientemente construido a expensas del rey, todo él de sillería con disposición semejante a un monasterio y con catedráticos grandemente famosos." ${ }^{1}$ Creemos que el favorable juicio estético que mereció a Münzer el edificio - "de bella apariencia" - fue inspirado porque su magnitud, solidez y dignidad arquitectónica y ciertos detalles ornamentales del interior, superaban en méritos a cuantos edificios escolares había conocido en sus viajes.

Conservó la forma que hemos descrito hasta principios del siglo xvi, cuando se realizaron las más importantes ampliaciones y reformas. Comenzaron éstas con las obras de la gran biblioteca, las que originaron la

1 J. Camón Aznar. Gula de Salamanca, 1982, p. 54. 
creación de la fachada plateresca y la construcción de la escalera monumental y de la galería occidental como vestíbulo y acceso a la biblioteca. (Esta galería fue prolongada en el siglo xix, por los restantes lados del claustro para satisfacer a las ampliaciones que entonces se realizaron, creando una segunda planta que se sobrepuso a la del edificio primitivo, lo que exigió construir de nuevo toda la fachada oriental. Con estas ampliaciones que fueron precedidas por la construcción de la casa rectoral, en el siglo xvir, la Universidad adquirio la forma que hoy tiene.) Las ampliaciones que se hicieron a principios del siglo Xvı, significaban no sólo el favor que los reyes concedian a El Estudio, sino también que la Universidad era un organismo en pleno crecimiento, que en aquellos años había llegado a su madurez dotado de extraordinaria vitalidad, en virtud de las excepcionales y favorables circunstancias históricas que existieron durante el reinado de los Reyes Católicos, las que propiciaban y exigían su desarrollo, espiritual y corpóreo, para poder cumplir su alta misión histórica, cultural y política, y proporcionar al reino, como más tarde al imperio, hombres doctos y letrados que en aquel momento eran indispensables para poder gobernar los inmensos territorios y las variadas naciones que dependian de España.

Como resultado de las ampliaciones realizadas en la primera mitad del siglo xvi, el edificio ganó en riqueza y amplitud, pero perdió el carácter y la unidad arquitectónica y especial que poseía la primitiva fábrica; siendo esto visible en el notable contraste que existe en el patio entre la galería baja, con sus severos arcos y pilares y la alta, con su elegancia palaciega, y el juguetón dinamismo de las arquerías.

Habiéndose originado las ampliaciones interiores y la construcción de la segunda portada con las obras de la biblioteca nueva, expondremos brevemente las razones que las motivaron y algunas de sus vicisitudes.

La primera biblioteca que tuvo la Universidad fue construida sobre la nave de la capilla. Quedó ésta parcialmente destruida con motivo de la colocación de un retablo, cuya altura excedía la del techo de la capilla, lo cual exigió la destrucción del piso de la biblioteca y causó su inutilización.

Por este motivo se acordó, en 1508, la construcción de una nueva, y, en 1509 , se decidió edificarla en alto, sobre el zaguán, y las aulas de leyes, Filosofía y Medicina. Su construcción debió durar hasta 1523 (fecha en que se contrataron vidrieras y se supone que en 1529 ya debía estar terminada.? 
La obra fue desde el comienzo objeto de preocupaciones, consultas y reparaciones por haberse advertido la debilidad estructural de su bóveda.

Aun cuando se menciona como única razón para la creación de la nueva librería la que hemos expuesto, podemos suponer, sin embargo, que también debió influir el extraordinario aumento que se habia producido durante aquellos años en la edición de libros, con motivo de la divulgación de la imprenta, lo cual exigiría una librería más espaciosa que la vieja.

\section{I.a fachada (generalidades)}

Con la construcción de la nave de la biblioteca se creó, en toda la longitud del ala occidental, un cuerpo de dos plantas en el centro del cual estaban la portada y el zaguán primitivos. En el muro exterior, para contrarrestar los empujes de la alta bóveda de la nueva librería, se elevaron robustos contrafuertes con pináculos y molduras góticas. La ampliación debió causar la destrucción, total o parcial, de la primitiva portada y originar la necesidad de construir una nueva, que debía corresponder por su forma y tamaño a las de la nave, y por su riqueza y señorio a las excepcionales circunstancias históricas que concurrían en el momento en que fue proyectada. Ambas condiciones explican algunas de sus características formales, pero no bastan para justificar la audacia y originalidad de la solución que se adoptó, que permitió lograr su perfección plástica, contribuyendo en gran medida a que alcanzase renombre universal.

En el momento en que fue construida existian ya varios ejemplos, algunos de ellos próximos y recientes - de suntuosas fachadas (como las de San Pablo y San Gregorio en Valladolid) que podían inspirar la plenitud de elementos ornamentales, pero no su singular posición-, pues aquéllas están adosadas a los edificios y enmarcadas entre contrafuer. tes. Si esta misma disposición se hubiera adoptado en la portada de la Universidad, habría quedado limitada y encogida entre los estribos, formando parte de una amplia superficie mural de tosca mampostería y no habría podido alcanzar sus armoniosas proporciones; la delicadeza de su talla y su expresión y significación estética, histórica y simbólica, habrian perdido fuerza $y$, sobre todo, al quedar subordinada al muro no habría logrado la orgullosa autonomia que la caracteriza, que constituye uno de sus más notables méritos.

2 M. Gómez Moreno. Catdlogo monumental de Salamanca, 1967, p. 231. 
Creemos que debieron ser estas consideraciones -junto al deseo de relacionarla con el espacio exterior-, las que inspiraron a su desconocido y genial autor y animaron a los patrocinadores a proyectar un cuerpo saliente sobre cuya superficie, un plano rectangular, pudiera desplegarse libre y generosamente, una composición, exuberante y delicada, plena de valores simbólicos; y someterla al mismo tiempo a una lógica ordenación renacentista. Debemos imaginar de este modo la razón de su originalidad, pues su disposición no es explicable por necesidades funcionales arquitectónicas, ya que la pequeña cámara que se formó entre la fachada y la biblioteca (cuyo destino inicial se desconoce y que estuvo dedicada a partir del siglo xvir a guardar los caudales universitarios en el "arca boba"), no justifica la necesidad de esta solución.

La dificultad de clasificar este singular elemento arquitectónico, ha motivado que los historiadores de arte se resistan a otorgarle la denominación de fachada. Al mismo tiempo la variedad de significados que sugieren su composición y ornamentación, ha permitido que le sean aplicadas las más diversas denominaciones. Examinaremos sucesivamente los dos aspectos y, para comprender el primero, expondremos un resumen de los más importantes significados que ha tenido la fachada arquitectónica a lo largo de la historia.

El concepto de fachada se aplicó, y se aplica en general, a las partes exteriores de un edificio y, en forma más restringida, a aquélla en que se encuentra la portada principal que insinúa, o muestra explícitamente, el carácter del cuerpo arquitectónico al que pertenece. En ciertas épocas las obras arquitectónicas carecieron de fachada relevante dotada de personalidad o de valor especial (o todas ellas eran equivalentes), el exterior de los edificios no poseía importancia expresiva, ornamental o simbólica, concentrándose en el interior todos los elementos significativos. En otras, la fachada y la portada eran como la "fisonomía" del edificio y sus rasgos la expresión "anímica", la proyección al exterior del contenido. Ha habido ciertos periodos en que dejó de ser el "rostro", vinculado de manera viva y orgánica a la interioridad, y se convirtió en una especie de "máscara" o "pantalla", dotada de gran expresividad, que se sobreponía artificiosamente al edificio, como un miembro postizo, independiente y extraño al contenido espacial y tectónico de la construcción. Este "fachadismo" permitia un más libre despliegue del vocabulario plástico, arquitectónico y ornamental, creando 
al mismo tiempo la posibilidad de que la portada principal no tuviera una posición determinada por la estructura y los ejes interiores, pudiendo ser dispuesta con mayor libertad (como ocurre con la del Colegio de San Gregorio de Valladolid, la cual es como una rica pantalla, sin relación axial con el edificio y también con la fachada salmantina de Sancti Spiritus).

La de la Universidad no puede ser incluida en ninguna de las clasificaciones anteriores, lo que explica la perplejidad de los escritores. Por su alejamiento del edificio y su autonomía no admite ser considerada estrictamente, ni como "rostro" ni como "máscara" (aunque por su posición axial está en correspondencia con el eje del claustro). Estas peculiaridades han permitido la interpretación que de ella han hecho notables tratadistas, cuyas opiniones transcribimos a continuación.

Casi nos cuesta darle el nombre de fachada -dice F. Chueca Goitiaque significa al fin y al cabo, prospecto de una interioridad, que en este caso no existe. Es la fachada sin nada detrás o mejor dicho con algo detrás que se trata de ocultar... es, en una palabra, lo menos arquitectónico que conocemos en este país, que sabe zafarse de la arquitectura con una despreocupación verdaderamente inaudita. ${ }^{3}$

Por su parte J. Camón Aznar, afirma:

Esta fachada no tiene más puntos de referencia que el expectador. Falta aqul esa misteriosa y orgánica correspondencia que se advierte en los mo mentos de los grandes estilos europeos, esa altiva unidad que determina en los ejemplares típicos de la mentalidad occidental la impresión de ser, todos los elementos de la construcción, resonancias unos de otros. Esta independencia del edificio libera al ornamentista de toda limitación y queda frente a un espacio a solas con su capricho.*

Por las opiniones expuestas podemos apreciar que esta "portada rica" (como la denominó Juan de Alava) posee, por la singularidad de su disposición, un altivo, indefinible y original significado que escapa a todo criterio tradicional. Sin duda para Juan de Alava y sus contemporáneos no hubo ambiguiedad, pues la consideraban como una portada dotada de plena autonomía para mostrar mejor su riqueza ornamental y simbólica, siendo natural que para ello se apartase del muro del edificio.

3 P. Chueca Goitia Arquitectura española del siglo xvi. Plus Ultra, 1953, p. 94.

•J. Camón Aznar. Op. cit., p. 32. 
Se han atribuido también a esta portada diversos significados y denominaciones por analogía o equivalencia -sugeridos por los valores plásticos y por el carácter de su ornamentación, y otros por su disposición general, o estructura _. F. Chueca Goitia la considera como una especie de retablo protorrenacentista "transcripción de lo eclesiástico a lo civil muy simple y pueril". Sin embargo, el mismo autor la interpreta de muy distinto modo cuando dice que es una "decoración colgada, formada por un enorme bastidor suspendido, del tipo de fachada estandarte del que había precedentes isabelinos, como la fachada de Santa María de Aranda de Duero, y la de San Gregorio en Valladolid"s (a los cuales podemos añadir entre otras las salmantinas de las Dueñas, Sancti Spiritus y el Corpus Christi).

A las precedentes interpretaciones $\mathrm{y}$ denominaciones añaden otros escritores las de tapiz - por la densidad y características de su ornamentación-, paño recamado o colgadura - por la analogia con la labor de bordado de la indumentaria de la época-, y algunos la califican de obra de orfebrería o de repujado por lo que sugieren el delicado y primoroso relieve de filigrana de algunas partes y el vigoroso y fuerte que posee en otras.

Vemos por lo expuesto que al mismo tiempo que se le niega título arquitectónico, se le prodigan numerosos apelativos correspondientes a otras artes: retablo, tapiz, estandarte, colgadura, paño recamado en oro, labor de filigrana, orfebrería y repujado... Todos estos títulos, equivalencias y analogias, pueden serle aplicados a esta obra, aunque ninguno la define plenamente, pues estando justificados todos ellos, no se logra expresarla cabalmente, ya que a la singularidad de su disposición se une la complejidad de valores y significados que posee, la densidad de contenidos plásticos y ornamentales y los diversos significados políticos, religiosos y culturales que en ella se acumulan como expresión artística de un excepcional momento histórico.

A las denominaciones anteriores nos permitimos agregar la de "Victor Máximo", pues con esta maravillosa portada en la que culmina el estilo plateresco, la Universidad manifestó jubilosamente su plenitud y universalidad. Con ella parece que quiso festejar y conmemorar su propio "doctorado", y presidiendo los vítores o aclamaciones que los nuevos doctores inscribian en rojo en los muros de las escuelas perpetuando su victoria académica, inscribió el suyo propio con relieves de oro.

5 F. Chueca Gotia, Op. cit., p. 97. 


\section{La ornamentación}

Los caracteres estilísticos y ornamentales de esta fachada representan una síntesis de las diversas corrientes arquitectónicas y ornamentales, nacionales y exóticas, que afluyeron a la arquitectura española a principios del siglo Xvi.

Su exuberancia decorativa conjuga en lo plateresco salmantino la herencia musulmana y mudéjar con los elementos del gótico florido y de lo isabelino, ordenados y equilibrados con el arte y la ciencia del renacimiento italiano, que empezaban a extenderse por la Península Ibérica. Todos estos factores fueron animados por la "pasión", que se atribuye a españoles y portugueses, por cubrir las superficies murales con abundante decoración que, siendo tal vez una característica esencial e intima de lo celtibérico, recibió de lo islámico mayor vitalidad y renovados impulsos.

Se ha pretendido, sin embargo, explicar única o especialmente la exuberancia ornamental de la portada como expresión de la idea -o más bien del sentimiento- que se denomina "Horror Vacui", concepto que designa la aversión de ciertos pueblos, o de algunos periodos culturales, a las superficies desnudas carentes de ornamentación. Creemos que esta interpretación -parcialmente aplicable en este caso- no es suficiente, como lo demuestran las solapas o márgenes deliberadamente desnudos que la bordean y limitan. Existe en cambio, a nuestro juicio, otra explicación de mayor validez que permite interpretar la profusión decorativa por razones muy distintas a las de ese concepto de la patología individual que se ha aplicado a lo supraindividual. Aunque no se puede rechazar la idea de que este sentimiento estuviera presente y activo en aquella época y ejerciese cierta influencia en el ánimo del autor, nos atrevemos a afirmar que la razón de su riqueza ornamental fue principalmente el afán o ansia de plenitud, riqueza y abundancia, originadas por la necesidad social de ostentación que caracteriza a la sociedad española de aquella época, que se sentía enriquecida, fortalecida y orgullosa al superar un periodo de luchas dinásticas, rebeliones de nobles insolentes y esfuerzos heroicos por lograr la total reconquista de la Península y por haber iniciado el descubrimiento y conquista de nuevos mundos. Se manifiesta de manera evidente este espíritu en el rico ropaje de las personas de elevada condición, que hacían con ello pública ostentación de riqueza y señorio, de importancia social y de caudales, que podemos ver en la indumentaria señorial y cortesana - $e$ incluso de la alta burguesía-, 
que se manifiesta también en los recargados paños recamados, domésticos y religiosos y en las ropas de los altos dignatarios eclesiásticos. (La severidad y austeridad, tanto en la indumentaria como en la arquitectura, que caracterizó el reinado de Felipe II, y fue limitada en las cortes y principados donde ejerció influencia, aún no había comenzado a manifestarse cuando la portada fue construida.)

AI igual que las personalidades y grupos privilegiados de la época, los edificios importantes de fines del siglo xv y principios del siglo XVI, tanto civiles como eclesiásticos, estaban obligados a mostrar también públicamente su señorío en la suntuosidad de un ropaje arquitectónico rico y galano. Este afán de riqueza y plenitud, cuyo proceso se advierte en Salamanca en la transición de los edificios nobiliarios de aquella época es principalmente el sentimiento que inspiró esta fachada y no el "Horror Vacui", como lo confirman las palabras de Juan de Alava, quien al referirse a ella, en 1529 , la llama "portada rica de las escuelas"."

Esta es la razón principal -que no excluye la influencia de lo morisco y de lo isabelino-, de la exuberancia ornamental de la portada universitaria; la ostentación del señorío que estaba obligada a mostrar una obra, cuya riqueza de valores representativos -monárquico, imperial, pontificio, artístico y científico-, exigía el más impresionante ropaje recamado en oro, comparable por su magnificenoia con la regia indumentaria de monarcas, emperadores y pontifices, y tan delicado y variado en filigrana como los mantos de las vírgenes o las vestiduras de las damas de la corte. La Universidad, en aquel momento -el más esplendoroso de su historia y de la de España-, estaba obligada a vestir las mejores y más costosas galas que el arte podía proporcionar y en ellas gastó la fabulosa suma de treinta mil ducados.

El vocabulario ornamental, ampliamente estudiado por varios autores, no deja de ofrecer, sin embargo, posibilidades de investigación, pues algunos de sus aspectos todavía permanecen imprecisos y oscuros. E1 lenguaje del plateresco -ornamental y no tectónico- empleado en esta fachada como en otras salmantinas, contiene, junto con modismos de estilos anteriores, vocablos y expresiones plásticas novedosas procedentes del Renacimiento italiano - conjugando lo toscano con lo milanés-, llegados directamente de Italia, o tal vez, a través de Francia. El problema de cómo llegaron no ha sido plenamente esclarecido y se ignora si

6 Carta de Juan de Alava a la Universidad. Archivo universitario salmantino. 
fue transmitido por tallistas expertos ya en este arte o fueron realizados por canteros del país que se inspiraron en grabados que por entonces divulgaron ampliamente por toda Europa, los motivos renacentistas italianos.

Sin embargo debemos suponer, por el arte con que están ejecutados, que no fueron manos de simples copistas las que lo realizaron, sino de artistas -fueran nacionales o extranjeros- que poseian gran práctica y habilidad. Es probable que tuvieran a la vista, como ejemplares, los grabados y estampas, no para ejecutar una copia servil, sino para inspirar su capacidad creativa (la creatividad no estaba reñida todavía con la imitación de la maestría ajena, aunque la originalidad y la personalidad de los artistas comenzaba entonces a adquirir valor). La gracia y elegancia de la ejecución de la mayor parte de los elementos ornamentales y la fuerza expresiva de otros, revelan la mano y el ingenio de verdaderos artistas, y decimos artistas en plural porque, a juzgar por las diferencias que existen, debieron ser varios, o al menos dos maestros o dos talleres los que realizaron la obra decorativa bajo la dirección del arquitecto (que pudo ser al mismo tiempo escultor), pues entre los adornos más finos y los de mayor bulto y las figuras, no solamente existen diferencias de tamaño y volumen sino de concepción plástica que revelan a distintos canteros con diferentes aptitudes $\mathrm{y}$ méritos. Es visible la mano maestra en la ejecución de ciertos motivos y parece indudable también que la originalidad de la disposición o estructura general, en la que habian de ser insertados, exclufa la simple imitación, o copia servil de modelos, pues aun admitiendo la existencia de éstos, era necesario adaptarlos a dimensiones que no podían estar previstas en los grabados, teniendo por lo tanto que interpretar y adaptar la temática, lo que exigia gran ingenio y originalidad.

La decoración italianizante, de grutescos, símbolos heráldicos, elementos vegetales y figuras fantásticas que se extienden por gran parte de la fachada; domina en todo el primer piso y se propaga y extiende por las pilastrillas y los frisos de manera casi uniforme. En el segundo - la zona imperial-, las figuras, simbolos y escudos llenan el campo y no dejan espacios libres para el despliegue de ornamentos. En el piso superior -el papal- los espacios libres proporcionan campo para una ornamentación más libre, movida y relevante, entre la cual se encuentran figuras monstruosas de oscura significación y la "fauna" que se 
propaga hasta la cornisa con su variado capricho sugiere la imagen de un campo misterioso, donde viven las criaturas del "monstruario medieval", en el cual es dificil penetrar y orientarse. Su exuberancia y su irracionalidad nos muestran la supervivencia en el plateresco de la fantasia y el misterio medievales, reanimados por la curiosidad, el asombro y las fábulas que produjeron las extrañas gentes y mundos entonces recién descubiertos.

Vemos, pues, cómo en esta fachada se acumulan y despliegan, visibles - semiocultos, los misteriosos sueños mágicos de los siglos anteriores que en aquel momento empiezan a retirarse a las profundidades íntimas, oscuras e inaccesibles. Junto a la claridad que preside la composición general, asoman aquí y allá semiocultos entre la ornamentación vegetal, seres fantásticos y monstruos que la ciencia renacentista no habia podido explicar y el arte no habia logrado todavia eliminar completamente.

Los elementos ornamentales llamados grutescos (tan abundantes y delicados en la fachada universitaria), aparecen al final de la época helenística y se emplean en Roma en los comienzos de la época imperial. Los ejemplos hallados durante el Renacimiento en las pinturas murales de algunos edificios romanos fueron denominados impropiamente grutescos por hallarse en edificios, en apariencia subterráneos, que por ello fueron llamados grutas. Fueron adoptados estos elementos ornamentales por los arquitectos renacentistas italianos especialmente en Toscana, Liguria, Roma y Lombardía y de alli se transmitieron a España en los primeros años del siglo xvi. En algunos casos la transmisión se produjo por escultores italianos que llegaron a la Península Ibérica para ejecutar obras arquitectónicas y ornamentales; en otros por medio de grabados que reproducían la ornamentación italiana, romana o renacentista, que fueron ejecutados por ornamentatistas españoles. Una de las fuentes más importantes de inspiración fue, probablemente, el Libro de dibujos o antigüedades de mano, llevado a España a fines del siglo xv que se encuentra en El Escorial, por lo cual es conocido con el nombre de Codex Escurialensis.

Los primeros ejemplos de talla ejecutados en España fueron realizados por artistas italianos en el palacio-castillo de la Calahorra, en la primera decena del siglo xvi, en la portada monumental que contiene el primer repertorio de figuras y ormamentos del vocabulario 
plateresco, algunas de las cuales están representadas en el mencionado códice.

Se mencionan como modelos de algunos relieves de la Universidad los grabados de Nicoletto de Modena, uno de los cuales (fechado en 1510) sirvió al parecer de ejemplo para uno de los paneles de la fachacla de la universidad y los de Israel van Meckenem (fechados en .1490), que fueron reproducidos en los bajorrelieves de la escalera universitaria.

\section{Gradaciones y jerarquias}

Al contemplar la fachada se percibe de inmediato la gradación ascendente del relieve, como un crescendo que va aumentando en volumen y sonoridad, en fuerza y énfasis. Esta característica peculiar -que no poseen otras fachadas contemporáneas- permite hacer igualmente visibles e inteligibles todos los elementos de la composición. La gradación asciende desde el detalle menudo, delicado y denso de la zona inferior, hasta el relieve máximo, de pleno bulto, de la parte superior; gradación cuantitativa, de lo casi bidimensional o pictórico, o a lo tridimensional o escultórico, que va unida a la disminución de la densidad de los elementos y motivos clecorativos. Esta solución fue sabiamente concebida y resuelta, de acuerdo con la visión y perspectiva renacentista y sus leyes de deformación, en función del espeotador, que se supone debe estar situado en el plano de la plaza sobre el eje de ésta y la fachada y a determinada distancia.

Además de esta gradación -fácilmente perceptible--, existe otra no menos importante, que consiste en el aumento de la expresividad plás. tica y "anímica" de las formas, símbolos y figuras, que constituye otra más de las muchas y muy notables sutilezas que posee esta portada. La efigie de los Reyes Católicos, en actitud hierática y con sonrisa convencional posee, por su delicado relieve, carácter simbólico de homenaje conmemorativo. A ello contribuye el haberse atenuado la expresión realista de retrato para idealizarlos y sustraerlos a lo temporal y contingente. La suave expresión plástica y el aire estereotipado les da cierto carácter estático, acentuando el sentido de estabilidad y permanencia: Fernando e Isabel, animadores de esta obra y fallecidos antes de ser realizada, pertenecían ya a la historia, que habían llenado más

7 Los datos anteriores han sido tomados de un estudio del señor Santiago Sebastián, profesor de la Universidad de Yale, sobre la decoración plateresca, publicado por la Universidad de Caracas. 
de un cuarto de siglo con su obra imperecedera. A diferencia de su imagen, los elementos y figuras del segundo cuerpo, especialmente las contenidas en las conchas, poseen mayor volumen y están dotadas de gran vivacidad y realismo; las cabezas, dinámicas y expresivas, se mueven y con su actitud y su mirada crean fuerzas que conducen en ciertas direcciones. Esta misma expresividad e inquietud se advierte también en los escudos y coronas, éstas de pleno bulto, que adquieren por ello mayor actualidad, como expresión viva del poder político entonces vigente. A diferencia del medallón de los Reyes Católicos que evoca la inmortalidad histórica de su reinado, la corona imperial representa la grandiosa y heterogénea realidad del imperio de Carlos V. Por último en la zona superior, la decoración, más relevante y vigorosa en todos los detalles, destaca la escena que representa a un papa rodeado de varios personajes dialogando con dos de ellos. Ésta por su mayor relieve y movimiento, y por la actitud y los gestos de las tres figuras -deliberadamente exagerados para destacar su presencia-, posee la máxima animación, expresión y movimiento, y su exaltación plástica puede ser calificada de barroca.

La doble y simultánea gradación y jerarquía, plástica y expresiva, se conjugan admirablemente y contribuyen, junto con la armoniosa ordenación estructural, a dar a la fachada, a pesar de su gran variedad de elementos y relaciones, unidad y armonía.

Se puede adventir que las gradaciones, tanto de volumen como de expresión, no se aplican a los elementos que forman el bastidor ni los marcos "estructurales" de la composición - pilastrillas, molduras y frisos-, cuya ornamentación de grutescos posee un delicado relieve uniforme, con lo cual se destaca el carácter "tectónico" de estos miembros y su neutralidad respecto de la composición y el simbolismo del conjunto. La misma uniformidad se advierte en los adornos - al parecer heráldicos-, que bordean exteriormente los marcos o molduras laterales, en los cuales se limitan, o más bien desvanecen, las superficies desnudas marginales, formando como un fleco que prolonga la ornamentación general, contenida y sujeta por dichos marcos, a los que rebasa, como si la decoración -el tapiz- se prolongase, evitando asi una brusca interrupción entre la parte ornamentada y las superficies yermas.

8 Según el escritor Enrique Sánchez Reyes, el pontífice representado es Martín V (1417-1481). Enrique Sánchez Reyes. La lección humana de la Universidad de Salamanca, 1967, p. 24. 


\section{Simbolismos}

El simbolismo general de la fachada se expresa de manera esencial por la división de la superficie total en tres pisos -zonas o campos-, que representan tres grandes espacios ideales de distinto valor y significación. El primero -el más próximo al espectador-, contiene solamente un elemento representativo y simbólico: el medallón de los Reyes Católicos -dos monarcas y un solo cetro-, con la leyenda: "Los Reyes a la Universidad ésta a los Reyes." Significa que estos monarcas fueron firmes sustantadores y protectores de los estudios y los principales animadores de esta obra, por cuyos méritos se encuentran situados en la zona básica, integramente dedicada a perpetuar su memoria y la gratitud de la Universidad. Su imagen, única en su campo, domina y reina en él sin rival que dispute su señorio, no admitiendo que otras figuras lo compartan y disminuyan la excepcional personalidad y significación de su reinado pues no necesitan de ninguna que legitime su poder y autoridad. La ornamentación de su campo, la más delicada y bella, forma como el celaje de un espacio irreal al que la finura y densidad del relieve, que parece recamado de filigrana de oro, da un aspecto y una profundidad evocadora de lejanía y de recuerdo de un reinado fabuloso e inolvidable.

Se sobrepone a este primer piso, apoyándose en él, el central e imperial. Es éste más movido, variado y abundante en figuras y elementos heráldicos, y de ornamentación más rala. En el centro campea orgulloso el gran escudo imperial con rica corona calada que constituye el centro simbólico (y también, como veremos, el geométrico de toda la fachada), escoltado por otros dos que ostentan águilas imperiales (el águila bicéfala imperial y el águila de San Juan de los Reyes Católicos). En Ios lados de esta zona hay dos medallones que, según algunos escritores, representan al emperador Carlos $\mathrm{V}$ y a su esposa Isabel (nieta de los Reyes Católicos). Las láureas que los rodean y la manera en que están representados, permiten suponer que son las efigies de dichos monarcas, aunque la libertad y poco realismo con que han sido realizados hacen difícil su identificación. Los cuatro bustos contenidos en conchas que se encuentran en la parte superior deben representar personajes históricos o mitológicos simbolizando valores o virtudes relacionados con lo cesáreo e imperial. Estas cabezas poseen gran movimiento y fuerte expresión, acentuadas por la forma y relieve de las conchas; con su 
dinamismo operan como elementos de transición hacia la exaltación desbordada, plástica y simbólica, del último piso. Éste, el más movido, complejo y barroco, posee gran variedad y densidad de contenidos simbólicos o alegóricos -algunos poco visibles, y de oscuro significado-, y su decoración floral y vegetal es más enfática. No está dividido verticalmente por pilastrillas y recuadros como los anteriores, por lo cual tiene mayor unidad y continuidad. Los dos pisos inferiores representan respectivamente lo regio y lo imperial, es decir, el poder secular y profano. Soportes simbólicos sirven de sostén a esta zona, la más elevada, la eclesiástica, universal, católica y pontificia. Simboliza el reino espiritual, más vasto, elevado, profundo y permanente que los inferiores, en el cual no caben divisiones, que serian heréticas. Está presidida por la figura de un pontífice inscrita en rico marco (adoctrinando desde la cátedra de San Pedro) formado por columnillas que sustentan un cerramiento mixto de arquitrabe y arco de medio punto, que ciñe un espacio ideal - símbolo de Roma-, que por su posición dominante sobre los demás poderes, expresa la autoridad de la Iglesia y de los papas sobre los reyes y la Universidad. Los cuatro medallones de esta zona, de oscuro simbolismo que debemos suponer se relacionan con lo eclesiástico y la historia sagrada, flanquean dos pequeñas esculturas desnudas, de las que se afirma representan a Venus y a Hércules ${ }^{\mathfrak{\theta}}$ hipótesis basada en la semejanza que poseen con dos figuras escultóricas del Renacimiento italiano aunque a nuestro entender deben representar personajes de la Historia Sagrada, tal vez Adán y Eva). Destacan ambas, a pesar de su pequeñez, por la forma rectangular del marco que les proporciona, dentro de la composición general, mayor peso y fuerza simbólica del que corresponde a su tamaño. Esta zona contiene entre la vigorosa ornamentación vegetal algunos símbolos y figuras monstruosas poco visibles y de difícil interpretación que no es posible enumerar y menos analizar en este breve estudio.

El simbolismo general de los tres pisos se sintetiza axialmente en la faja vertical, que constituye el eje geométrico de simetría de toda la composición. En ella se encuentran en orden jerárquico ascendente el medallón de los Reyes Católicos; el escudo imperial, y la figura del papa. Esta faja, que es la más ancha de las formadas por las pilastrillas en los dos primeros pisos, se continúa en el último con las columnas

- El Hercules Farnesio de Lisipo, cuyo dibujo se encuentra en el Codex Escurialensis y que aparece en bajo relieve en la portada del Palacio de la Calahorra, es idéntico al de la Universidad. 
que limitan el ámbito pontificio, concentrando en relación jerárquica ascendente la sustancia simbólica de la fachada. A este esquema vertical debe añadirse para completar el simbolismo, el eje horizontal que forman los escudos y los medallones del cuerpo central, con el cual queda definida una cruz que completa los ejes simbólicos.

Sobre el último piso sobresale una vigorosa y rica cornisa y alero, profusamente ornamentada en la que, entre figuras caprichosas, o monstruosas, aparecen risueñas cabezas de ángeles o querubines, que rematan jubilosamente la rica portada y su compleja significación simbólica, insinuando el ámbito o reino celestial en el cual culmina la gradación plástica y simbólica que hemos descrito.

Sobre la cornisa se eleva la crestería con flameros, a la cual se puede atribuir también una significación simbólica, que se comprende mejor al compararla con la del inmediato hospital de El Estudio. Esta, por su gran dinamismo y expresión y por la fantasia de sus formas recortadas, parece estar dotada de movimiento, produciendo la sensación cinematográfica de correr sobre el alero: La de la portada universitaria, por el contrario, posee un carácter estático y un aire majestuoso por ser la corona que ciñe la regia fachada; es como la suma o resumen de la corona real de los Reyes Católicos, de la imperial de Carlos V y de la tiara pontificia. Este es el significado simbólico que mejor corresponde a nuestro entender a esta crestería que remata la portada y que desbordando altiva la superficie del sólido muro eleva hacia el cielo sus orgullosos pináculos y flameros.

\section{La fachada como texto (los humanistas)}

Así como los arquitectos, maestros de obra y escultores medievales se veían obligados a solicitar el consejo de religiosos para la correcta representación de la iconografía y de las escenas sagradas; los arquitectos renacentistas necesitaban la ayuda de los humanistas para la representación de personajes y símbolos de la antigüedad clásica.

Podemos suponer, por lo tanto, que el autor de la fachada debió contar, desde el primer momento, con la colaboración de un erudito humanista que inspiró y orientó la selección de los motivos, temas y personajes históricos y mitológicos que habían de figurar en ella. Confirmada la participación que tuvo por entonces Fernán Pérez de Oliva, en la elaboración de los simbolismos del antepecho de la galería alta -los famosos "enigmas"-, y habiéndosele atribuido las ideas para 
los medallones del Colegio Mayor de Santiago (del arzobispo Fonseca), no es aventurado suponer que fuese dicha personalidad universitaria la que inspiró los principales elementos simbólicos y alegóricos. ${ }^{10}$ Esto reafirma nuestra opinión (en contradicción con la de otros autores) de que la simbología de esta obra fue concebida y prevista de antemano de acuerdo con un plan, no siendo por lo tanto, como se afirma, producto del azar y obra de relleno.

Al proyectar la portada con su variedad de valores y significados, se pretendió hacer de ella un texto académico - mezclando vocablos griegos y latinos y la sintaxis toscana con el noble y recio castellano-, para expresar y hacer legible e inteligible la significación histórica de la obra. Se continuó de este modo la tradición medieval que hizo de los tímpanos, las arquivoltas y otras partes de las catedrales góticas, el escenario para presentar personajes y escenas religiosas y episodios evangélicos, creando un texto teológico e histórico para educar e impresionar a los fieles, que era como "una Biblia para los iletrados". Pero siendo esta obra un producto del Renacimiento, inspirada por el humanismo y teniendo carácter civil y académico, fue "redactada", "escrita" e "impresa" como la página de un libro docto, dirigido a bachilleres, licenciados y doctores; a letrados que sabían del griego y el latín, por lo cual toda la portada se cubrió de simbolos y personajes de la antigüedad formando el cortejo que acrecentaba la legitimidad y grandeza histórica de los monarcas y pontífices allí representados y de la propia Universidad. Sin embargo, junto a la erudición un poco pedante y rebuscada de las citas greco-romanas, se conservaron -como residuo del medievo, que el pensamiento y el arte español no habían logrado superar-, las fantásticas criaturas de los tenebrosos siglos anteriores divulgadas por los "monstruarios", que añaden a la claridad, lógica y racionalidad de lo renacentista un fondo inquietante, misterioso e

10 Fernán Pérez de Oliva, Natural de Córdoba donde nació hacia el año de 1492; a los 12 años estadista ya en la Universidad de Salamanca de donde pasó a Alcalá, Parls y Roma; en este último punto se le ofrecicron los destinos que desempeñaba un tío suyo en la corte de León $X$ y volvió a París, donde se dedicó a la enseñanza: enterado Adrano VI de su mérito, quiso llevarle a Roma dándole buen destino eclesiástico, pero renunció segunda vez y vino a Salamanca entrando en el Colegio del Arzobispo, llegando a ser catedrático de moral y rector de la Universidad, pero apenas llegó a este puesto, le arrebató la muerte prematura el año 1530. Escribió varias obras sobre temas diversos cntre ellos el Didlogo de la dignidad del hombre. MEMORIA HISTORICA DE LA UNIVERSIDAD DE SALAMANCA POR DON ALEJANDRO VIDAL Y DIAZ. SALAMANCA 1869. P. 237. 
irracional. La simultaneidad de los dos aspeotos viene a ser elocuente expresión del carácter contradictorio de la cultura española en el momento en que la tradición medieval y la innovación renacentista pareclan reclamar iguales derechos.

Este texto resumido en la rica portada miniada, debió ser inteligible entonces para maestros, escolares y gentes doctas en lenguas clásicas y conocedores de lo toscano y lo romano, que podian traducirlo al lenguaje vulgar; pero, a diferencia de los pórticos medievales, que los creyentes seguramente aprendian de memoria, éste no debió ser comprensible por los iletrados, por lo cual nunca se vulgarizó. Con el correr del tiempo incluso los maestros universitarios debieron perder interés por la traducción u olvidarla perdiendo la fachada poco a poco el valor ilustrativo y educativo que se pretendía darle, quedando reducida a sus valores plásticos formales y estéticos.

\section{Estructura ${ }^{11}$}

En la ordenada composición de la fachada y en sus proporciones y ritmos, se manifiesta la racionalidad estética del Renacimiento que, en lo superficial, comenzaba a aplicarse en la arquitectura española. Reducida a sus elementos más simples podemos percibir un entramado o retícula de barras que forman un armazón estructural. Esta disposición es la que ha permitido definirla de dos maneras: como un bastidor sujeto al plano del muro; es decir, que los miembros que la estructuran no se apoyan en el piso ni ejercen, por lo tanto, función de soportes sustentantes, y también como una colgadura suspendida de la cornisa o alero, sujeta y ceñida por prendedores, bandas o ceñidores.

El bastidor está formado por las pilastrillas y frisos y limitado por dos relevantes molduras verticales que ejercen la función de marcos, y junto con el sistema de pilastrillas completan el bastidor, en cuyos encuadramientos se despliegan los elementos decorativos y simbólicos. Las grandes molduras laterales no se interrumpen al nivel de las arquivoltas de las puertas, sino que se prolongan hasta la altura de la imposta apoyándose en exornados repisones. Con este artificio se prolonga también, aparente o ilusoriamente, la zona rica, para acentuar su sentido de verticalidad, efecto al que contribuye el que la banda o friso

11 Hemos venido aplicando los términos tectónica y estructura a elementos de esta portada, aunque no poseen significación constructiva, ni función mecánica, porquc su evidente carácter de soportes ideales y de elementos de articulación lo justifican, y no pueden ser concebidos ni definidos de otro modo. 
horizontal que corre por encima de las puertas quede interrumpida en dichas molduras. Las zonas laterales, o márgenes, contribuyen al mismo efecto, aun cuando para evitar que este acento fuera excesivo se buscó equilibrar la relación horizontal-vertical, atenuando ésta mediante la prolongación de los dos frisos centrales que rebasando las molduras, o sujetadores, se prolongan hasta el borde; de este modo se neutralizó y atenuó delicadamente el sentido ascendente, manteniendo, sin embargo, cierta tensión dinámica que evita el equilibrio inerte.

La articulación y aparente función tectónica, que ejercen las pilastrillas, recuerdan la primera aplicación que hizo Alberti de este recurso en la fachada del Palacio Ruccelai, en Florencia, y más tarde Bramante en la Cancillería, en Roma. Este, y otros aspectos de orden armónico y proporcional permiten advertir las influencias estilisticas y los criterios estéticos del Renacimiento italiano aplicados a una estructura no arquitectónica.

\section{Los márgenes}

En los análisis precedentes nos hemos referido especialmente a los elementos ornamentales y a la superficie que éstos cubren. Asf es, en general, vista por los espectadores, desdeñando los espacios marginales, carentes de decoración, como elementos superfluos. Resulta incompleto el análisis si, con visión limitada, se ignora el importante papel que las superficies laterales desnudas tienen en el valor de esta obra. Si no existieran, la fachada se proyectaría sobre el tosco muro de la biblioteca; perdería su orgullosa autonomía -más bien soberanía- al mezclarse, en continuidad visual, con la pobreza de los paramentos del fonclo y con los ventanales y contrafuertes de carácter tan diferente. Su majestuosidad exigía el aislamiento, y para ello hubo de rodearse de estas zonas laterales, en las que quedó descubierta y visible la limpia sillería del plano de la fachada. No son, por lo tanto, elementos pasivos ni áreas neutras, sino plenamente activas, y aunque su papel sea poco brillante no es por ello menos valioso, pues la riqueza de la fachada no brillaría tanto sin la sobriedad de estos márgenes que la escoltan y protegen.

Se debe destacar también otro interesante detalle que contribuye muy sutilmente al efecto general. El plano de la fachada está limitado en los bordes por una ligera moldura, casi imperceptible; esta moldura 
elimina la arista viva, evita su dureza, e insinúa una cierta continuidad tridimensional más allá del borde. A este efecto contribuyen también los dos frisos o ceñidores centrales que la abrazan y la cornisa superior y la crestería que al prolongarse, aunque brevemente, en los costados da al plano cierta corporeidad e insinúa de manera sutil que su alejamiento del cuerpo de la Universidad no significa extrañamiento ni aislarse de ella.

\section{Las puertus}

La superficie rica de la portada, a pesar de la fuerza que sugieren los elementos que aparentemente la sujetan y ciñen, posee cierto peso que parece ejercer presión sobre los arcos de las puertas. Esta acción aparente, que podemos calificar de mecánica, debió ser prevista al proyectar la obra y determinó, a nuestro juicio, la forma de los arcos. Estos -carpaneles, o apainelados-, de escaso peralte, usuales en el plateresco salmantino, corresponden lógicamente por su forma a los esfuerzos y tensiones visuales y también a la armonía y equilibrio general de la composición. Parecen ceder deprimidos al peso e importancia de la mag. nifica carga que soportan, resignados a cumplir modestamente el papel de elementos funcionales. Si las puertas hubieran poseido arcos de medio punto, o apuntados, más orgullosos y altaneros, habrian creado una tensión o fuerza ascendente; sus contornos, demasiado ostensibles, habrian perturbado la relación de fuerzas que predominan y su mayor altura habría alterado las proporciones de todos los elementos.

La entrada, con sus dos puentas - tal vez concebidas para desfiles procesionales o ceremoniales-, separadas por un pilar, que recuerda los maineles góticos, posee solamente una fina decoración en las arquivoltas y nervaduras de las jambas; y los muros laterales que la flanquean carecen de todo ornamento hasta la altura de la imposta, donde se encuentra la ménsula o repisón en que se inicia la rica portada. La sobriedad de la parte baja destaca claramente el carácter funcional y utilitario de la entrada, y hace visible que la portada comienza en la imposta de las puertas y termina en la crestería. Los muros laterales se prolongan en los que limitan el recinto coronado por almenas que simbolizan el fuero que poseía la Universidad, y evocan la multitud de privilegios y exenciones de que gozaban la institución, sus maestros y escolares y contribuyen también, como dos pequeñas alas horizontales al equilibrio general de la portada. 


\section{Sobre el autor}

No solamente se ha negado a la portada de la Universidad el título de obra arquitectónica, sino que se ha negado a su autor la categoría de arquitecto, afirmando que es obra de constructor de retablos o de simple ornamentista. Esta idea la expone un notable arquitecto y distinguido escritor del siguiente modo:

En esta obra no existe de ningún modo una idea arquitectónica sino una transcripción a la arquitectura de esquemas y fórniulas de las artes menores. En torno a los autores de esta fachada reina la más absoluta oscuridad. Esto es comprensible toda vez que en España no había en aquellos tiempos maestros formados en el nuevo estilo, verdaderos arquitectos de educación clásica y los que venían del extranjero eran meramente entalladores, ornamentistas imagineros, pero nunca arquitectos, por eso sucede que al lado de torpezas e indecisiones de composición, al lado de goticismos no desarraigados, nos encontramos con primores decorativos de la más legítima toscaneidad, grutescos llegados con toda su exquisita fragancia original. Este es el caso de la fachada de la Universidad, pobreza y aridez, en la invención arquitectónica junto con la más cadenciosa, suave, flexible e inteligente decoración sobre todo floral.12

Un renombrado profesor que investigó sobre el anónimo autor, o autores, de la fachada las relaciona con los que trabajaron en retablos y obra ornamental para el obispo Rodríguez de Fonseca en la catedral de Palencia hacia 1513. Rehusando admitir que su autor fuera un ar. quitecto, afirma que se ignoran los nombres de sus autores (aunque Quadrado y Bertaux la atribuyen a Egas) y supone que fueron dos los maestros, separados en el tiempo, de los cuales la obra primitiva, o sea la del primer cuerpo, fue de autor desconocido y el resto lo atribuye a Juan Gil hijo, autor de la fachada de Sancti Spiritus. ${ }^{13}$ Otro famoso escritor alentado con la idea fija por descubrir al autor revisó el archivo de la Universidad, sólo era descubrir como de costumbre, que esto es precisamente lo que ahí no consta, lo único que puede inducirse es que se hizo después de la librería, coincidiendo con el vacío de los libros de claustros de 1513 a 1525, y afirma de manera rotunda: "Sin ser muy lince se comprende que aquello es obra de adornista y no de constructor, así se perdona lo trivial, insulso y nimio de su traza como ideadas

12 F. Chueca Goitia. Op. cit., p. 42.

13 J. Camón Aznar Op cit., p. 37 
por quien no sabía más que llenar superficies de adorno y aun esto en escala corta y a lo primoroso." 14

En nuestra opinión la sabiduría y sutileza de la ordenación, la atrevida y original relación de la fachada con el cuerpo de la biblioteca y con el ambiente exterior, permiten creer que el autor no era un simple cantero auxiliar, ni mero entallador "sin otra capacidad que la de llenar superficies con adornos". Si no fueran suficientes estas razones para reconocer la ciencia, el arte y la experiencia de un arquitecto lo confirmaría la armoniosa estructuración de los elementos "tectónicos" que la organizan, en la cual no advertimos "torpezas e indecisiones" y en la que es fácil ver que están inspiradas en principios y fórmulas de los arquitectos renacentistas italianos; que sólo un arquitecto podía aplicar con tanta seguridad. El hecho, innegable, de la débil relación con la exterioridad e interioridad del edificio y su carencia de contenido espacial, indican solamente que el autor, enfrentado a un problema y a un programa insólitos, tuvo que desplegar su ciencia por medios exclusivamente formales, y con recursos pictóricos y concebir las relaciones espaciales, posición de la fachada y ámbito exterior con recursos originales. Sin embargo, el ingenio y el arte con que manejó, conjugó y expresó todos los factores para llegar a tan extraordinaria solución; la sabia gradación de volúmenes de acuerdo con las leyes de la perspectiva, y el cálculo de las deformaciones visuales, demuestran, a nuestro entender, que no fue obra de simple ornamentista sino de verdadero arquitecto como lo reconocen implícitamente Chueca Goitia y Camón Aznar, cuando afirman que fue concebida en función de un espacio y un espectador, factores que no eran considerados, o lo eran de manera insuficiente, por los simples entalladores y adornistas.

El supuesto de que fuese un arquitecto el autor del proyecto, y director de la obra, no excluye la posibilidad - tan frecuente entoncesde que fuese también cantero, escultor y tallista y ejecutase como tal, parte de la obra. Esta posibilidad es muy verosímil pues para lograr la extraordinaria unidad y armonía de la ornamentación y la ordenación general debia poseer profundos conocimientos en ambas disciplinas.

Ha resultado hasta ahora inútil la busca del autor entre los ornamentistas lo cual sería suficiente, aunque no hubiera otras razones, para buscarlo entre los arquitectos. Esto es lo que hemos intentado, guiados 
por la convicción de que fue uno de los más notables de aquella época el que proyectó y realizó la obra, auxiliado por notabilísimos tallistas. Nuestro criterio se funda, en primer lugar, en que encontrándose por entonces en Salamanca, varios de los más renombrados arquitectos del reino, y algunos de ellos dedicados a los trabajos más importantes que entonces se realizaban en la ciudad, parece natural que fuese uno de ellos el que hiciera el proyecto o traza y asumiera la dirección de los trabajos. ${ }^{15}$ Camón Aznar insinúa que el gran arquitecto y gran tallista Juan Gil de Ontañón hijo, autor de la fachada de Sancti Spiritus, pudo ser el autor de la parte superior de la portada, extraña hipótesis mediante la cual atribuye participación en la obra a tan notabilísimo arquitecto, pero solamente a título auxiliar como ornamentista, y bajo la dirección de anónimo tallista.

Entre los arquitectos que realizaron por entonces las más importantes obras salmantinas se perfila Juan de Alava como el presunto autor, aunque no existe ninguna evidencia. Nuestra hipótesis se funda en los datos que poseemos sobre su personalidad y en las obras realizadas en Salamanca desde 1505 hasta su fallecimiento en 1531, así como en las características de su estilo. Los datos y fechas que vamos a exponer tienen por objeto demostrar lo verosímil de nuestra conjetura. Participa de 1510 a 1512 en la polémica suscitada sobre el proyecto elaborado por Anton Egas y Alonso Rodríguez sobre el emplazamiento y traza de ia catedral nueva y junto con los arquitectos anteriormente mencionados fija en 1512 la traza definitiva; en 1513 participaba Juan de Alava activamente en las obras de la catedral nueva y en 1520 se le obligó a cerrar las tres capillas que estaba construyendo; en las que no disimuló su predilección por los adornos del Renacimiento, frente a las cuales Gil de Ontañón construía al mismo tiempo con carácter goticista las suyas.

Es mencionado también en relación con el Colegio de Santiago o del arzobispo Fonseca (del que se supone fueron autores Alonso de Covarrubias, Pedro de Ibarra y Rodrigo Gil de Ontañón), obra que se inició al mismo tiempo que se construía la portada universitaria y en cuyo zaguán y portada de la capilla se imitaron la ornamentación de la Uni. versidad y de la fachada de San Esteban. Estos datos reafirman la no-

15 Con motivo del proyecto de la nueva catedral, Fernando el Católico, en 1509 ordenó a Anton Egas que hiciera las trazas de la catedral que fueron trazas consultadas con Juan Gil de Ontañón, Juan de Alava, Alonso Covarruvias, Juan de Badajoz, Juan Sarabia, Juan Tornero y Juan Campero. 
table y constante participación que tuvo Alava en los más importantes edificios construidos en su tiempo lo cual, junto a las caracteristicas de su estilo, hace creible la posibilidad de que fuera el autor de la portada universitaria. Un apoyo más para nuestra hipótesis lo proporciona la casi constante participación que tuvo en las obras que se realizaron en la Universidad desde los primeros años del siglo xvi. Aparece su nombre por primera vez en 1506 en relación con las obras de la sacristía de la capilla con el título de cantero. Es consultado junto con Juan Gil, para dictaminar sobre la forma de remediar los peligrosos defectos de construcción que se observaron en 1527 en la nueva libreria, habiéndosele otorgado el nombramiento de maestro de la obra. Ésta es una razón más que permite asociar el nombre de Juan de Alava y su actividad con la fachada universitaria tan intimamente vinculada con la nueva biblioteca.

Su constante relación profesional con la Universidad queda en evidencia en la expresión que empleó en uno de sus informes al decir que "estaba obligaclo a servir a la Universidad de Salamanca por ser vecino de esta". ${ }^{16}$ En 1529, año en que se supone ya estaba terminada la portada, Juan de Alava informa lo siguiente: "Ast mismo e mirado que la capilla bóveda pequeña que está sobre la portada rica de las Escuelas... no tiene por donde subir a ella para entrastejar se debe elegir un usillo en el callejón que está entre la Librería y la calle afirmando y alli con un rincón de la portada". ${ }^{17}$ No podemos creer que tan notable, renombrado y solicitado arquitecto fuese simple o mero consultor para estos pequeños detalles constructivos de no haber participado de manera más importante en la realización de la obra de la portada, y ser por ello conocedor de estos aspectos.

Juan de Alava fue el autor de la traza del convento e iglesia de San Esteban sobre cuya portada el propio Gómez Moreno dice lo siguiente:

La gran fachada es obra maestra de Alava y la más admirable quizá como conjunto decorativo dentro de su género; Alava era un modernista, un impresionista profundo y delicado; pilastras, columnas y entablamentos no son miembros de sustentación en una fachada y aqui no lo disimulan ofreciéndose a la vista delegados de tenue saliente y llenos de adornos, pues que adorno son ellos mismos; la unidad preside, por caso raro en su traza, de modo que todo encaja en lugar propio y con valor adecuado a su fun-

16 Documento del Archivo de la Universidad de Salamanca.

17 Documento del Archivo de la Universidad de Salamanca. 
ción... en pormenores de ornato y escultura decae esta portada respecto de las otras coetaneas de Siloe, Riaño, Covarrubias y otros y muy especialmente respecto de la fachada de la Universidad donde parece haberse inspirado con preferencia. ${ }^{1.8}$

En la anterior descripción podemos advertir que se pone en evidencia la relación que existe en la ordenación y el significado de los elementos de ambas fachadas y se afirma que la universitaria sirvió de fuente de inspiración. Nosotros no vemos solamente fuente de inspiración, sino que nos atrevemos a ver en ambas obras a un mismo autor que por ello, y a pesar de las diferencias tan notables que existen en la concepción de ambas fachadas, tienen evidentemente en común la lógica y la relación y composición del empleo de ciertos elementos y proporciones en la ordenación general.

No es solimente Gómez Moreno el que destaca la relación de analogía entre las dos fachadas; varios autores coinciden con él y aun cuando ninguno de cllos reconoce a Alava como autor de la portada universitaria sino que más bien reiteran el anonimato del autor, no pueden, sin embargo, dejar de comparar la portada de San Esteban, proyecto indudable de Juan de Alava en su traza general, con la fachada universitaria, y se ven obligados a establecer una relación de parentesco o de analogía sin que expliquen por qué Juan de Alava tenía necesidad de inspirarse en obra ajena dada la indiscutible personalidad que poseía.

Nuestro intento por esclarecer la personalidad del autor de la portada universitaria tiende, en primer término, a demostrar que esta obra no es -como dicen los autores citados y otros que no hemos mencionado- obra de mero ornamentista, entallador o autor de retablos, y que su autor debió ser un gran arquitecto; y, en segundo lugar, que dadas las circunstancias que concurren en Juan de Alava -y aunque ello no proporciona la evidencia- pudo ser éste el anónimo autor.

\section{El patio y la fachada}

La placita en que se mira la portada lleva el nombre de las Escuelas Menores, porque en ella se encuentra la más notable, y el de Patio, por ser parte de la interioridad e intimidad del ámbito universitario. Por su forma y proporciones está vinculado de manera tan natural y necesa-

18 M. Gómez Moreno. Op cit., p. 130. 
ria a la portada, que resulta dificil imaginar la existencia del uno sin la otra, pues por su dependencia recíproca forman una unidad espacial y arquitectónica, tan lógica y armoniosa, que parecen vinculados orgánicamente de manera indisoluble. Se sabe que el patio fue abierto por la Universidad a principios del siglo xvir, mediante el derribo de las casas que estaban enfrente de la portada. ${ }^{19}$ A pesar de los testimonios que existen sobre la fecha en que se realizó esta obra creemos, sin embargo (aunque no poseemos pruebas de ello), que al construirse la portada de El Estudio y como su complemento necesario, debió existir el propósito y tal vez el plan, de crear dicho espacio; pues era indispensable para que tan rica obra pudiera ser contemplada y admirada. De otro modo resultarían inexplicables la singular solución que se dio al conjunto de la portada saliendo hacia el exterior y las proporciones, com. posición y gradación de relieve que fueron concebidas para ser vistos a una distancia que excedía considerablemente a la de la angosta calle y exigía el espacio libre para dar al espectador el punto de vista más favorable. La estrecha calle de Libreros no ofrecía una perspectiva adecuada para ello, por lo cual la existencia misma de la portada perdía una de las razones fundamentales de su existencia; la de ser vista en conjunto y en todos sus detalles, admirada por su galanura y leida como un texto; carecería por lo tanto de sentido el esmero y la delicadeza de su relieve, la ciencia de su composición y el valor de sus símbolos, y resultaría inconcebible haber gastado en ella la fabulosa cantidad de 30000 ducados para engalanarla si sus galas no podían ser admiradas. Estas razones nos reafirman en la hipótesis de que la creación de este patio, o al menos de un espacio abierto frente a la fachada, debió estar prevista por el autor y los patrocinadores, aunque por razones que ignoramos el patio no fue abierto sino un siglo después. ${ }^{20}$

19 Documento CXV, del Archivo Universitario. Don Felipe, por la gracia de Dios, etcétera, etcétera, vista la relación enviada por la Universidad de Salamanca, lo pedido por el fiscal de nuestro consejo, el licenciado Melchor de Molina y la aprobación de las fianzas de los maestros encargados de las obras de la plaza de las escuelas, hecha por el doctor Ramos, alcalde mayor de Salamanca, damos licencia a la dicha universidad para que prosiga la indicada obra conforme la traza que va firmada de Juan Gallo de Andrada. Dada en Madrid a 21 de mayo de 1611, Firmada por los del consejo.

20 Esta plaza no existía, cuando se edificaron las escuelas y el hospital, pues consta que para realizarla se obtuvo del rey Felipe III auto del $\$ 1$ de octubre de 1509, por el que dio licencia para obras de la plaza, proyectada de la Universidad, y mandó se enviara relación al consejo de las trazas, pidiendo se explicaran las razones. A pesar del mal estado de la hacienda de la Universidad debió ser costoso el proyecto que en 
La solución que se dio al patio (ignoramos si corresponde a la que imaginó el autor de la portada) definió la plaza, teniendo como eje el de la fachada, y sus dimensiones y proporciones armonizaron con ella y con los edificios, que completaron el patio, por la sobriedad de sus fachadas y su altura, sensiblemente igual a la del hospital de El Estudio y de las escuelas no menores, contribuyeron a la unidad y regularidad del conjunto y a la creación del punto ideal de observación y contemplación de la portada que vino a corresponder aproximadamente con el centro mismo del patio.

Las aristas o esquinas que forman los edificios del patio con la calle de Libreros forman también el límite del campo visual adecuado para gozar de la contemplación, sin que la fachada se vea dominada o desbordada excesivamente por las superficies del segundo término. Las esquinas forman, por lo tanto, como un marco que limita y conduce la visión hacia la fachada sin que otros elementos la distraigan. Al mismo tiempo el dinamismo de las líneas perpendiculares al edificio universitario contribuyen con su escorzo a orientar la mirada del espectador y aquietarse en la reposada y estática sensación que produce la fachada en su conjunto vista frontalmente.

El carácter semicerrado de la plaza, abierta solamente hacia la fachada, contribuye también a centrar el interés del espectador al impedir el camino hacia un alejamiento excesivo o huida que produciria una visión lejana, empequeñecicla, obligándole a verla a tal distancia que en ningún caso disminuya excesivamente su tamaño aparente, ni pierda su interés. Las relaciones del patio con la fachada -como las que presidieron la organización de ésta- están de acuerdo con las leyes y criterios renacentistas sobre la perspectiva central. Sus dimensiones, composición y ornamentación, concebidas pictóricamente sobre una superficie plana rigurosamente limitada, exigian la aplicación de la ciencia de la visión, tal como fue desarrollada por los artistas italianos en el siglo xv. De acuerdo con dichas leyes geométricas, el centro focal debería estar situado a una distancia equivalente a vez y media la mayor dimensión del tema, en este caso la altura. Esta condición se satisface muy aproximadamente en un punto situado sobre el eje de la fachada

1611 se autorizo la continuación de las obras, de acuerdo con los planos firmados por Juan Gallo de Andrada Esperabe de Arteaga, Enrique. Historia prismdtica $e$ interna de la Universidad de Salamanca, Vol. I, núm. 683 y 688, Salamanca 1914. También hay referencias documentales en Regesta... documentos 588, 594 y 596. J. A1varez Villar La Universidad de Salamanca. 
DOI: http://dx.doi.org/10.22201/iie.18703062e.1974.43.998

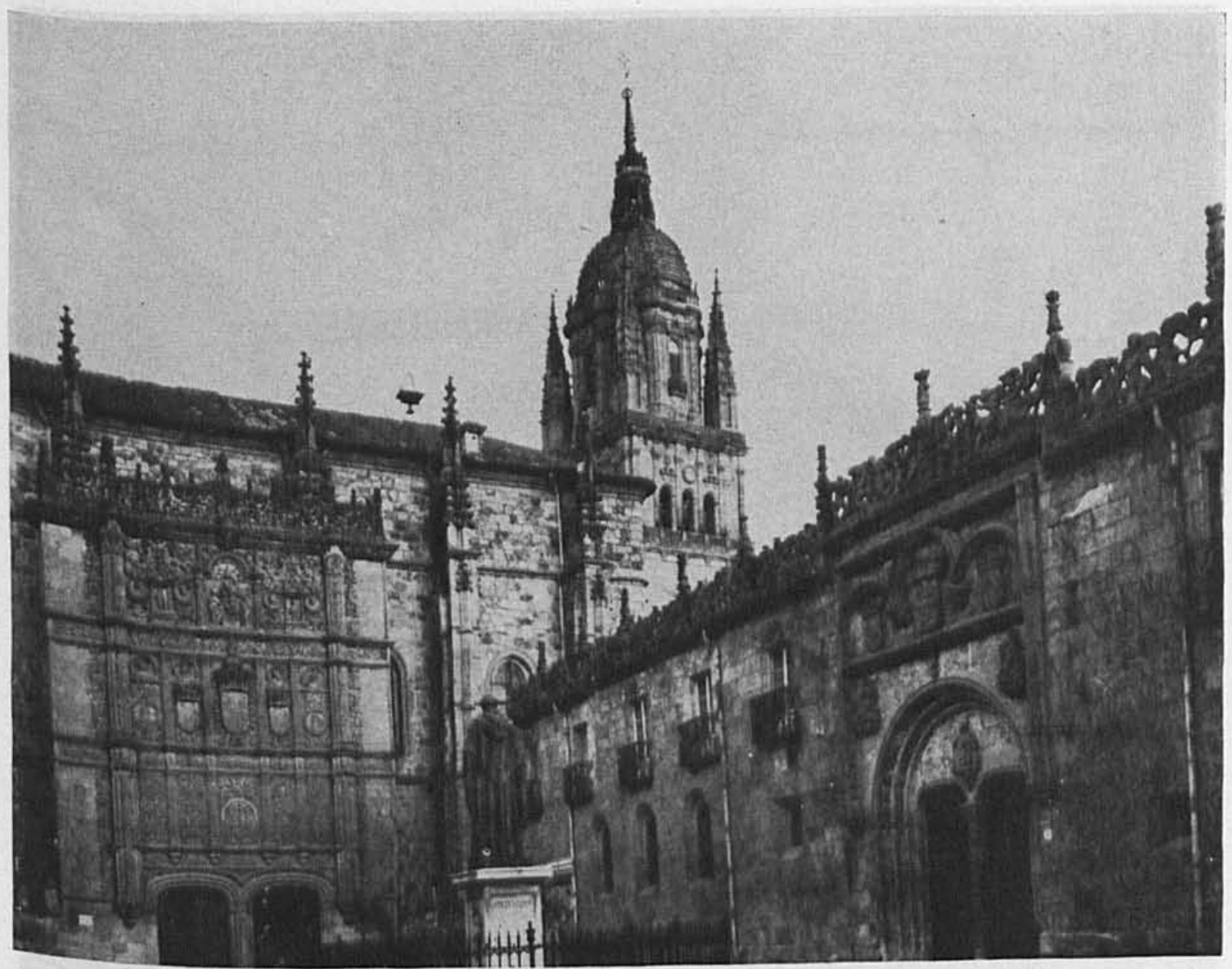

1. Fachada y vista parcial de las escuelas menores 


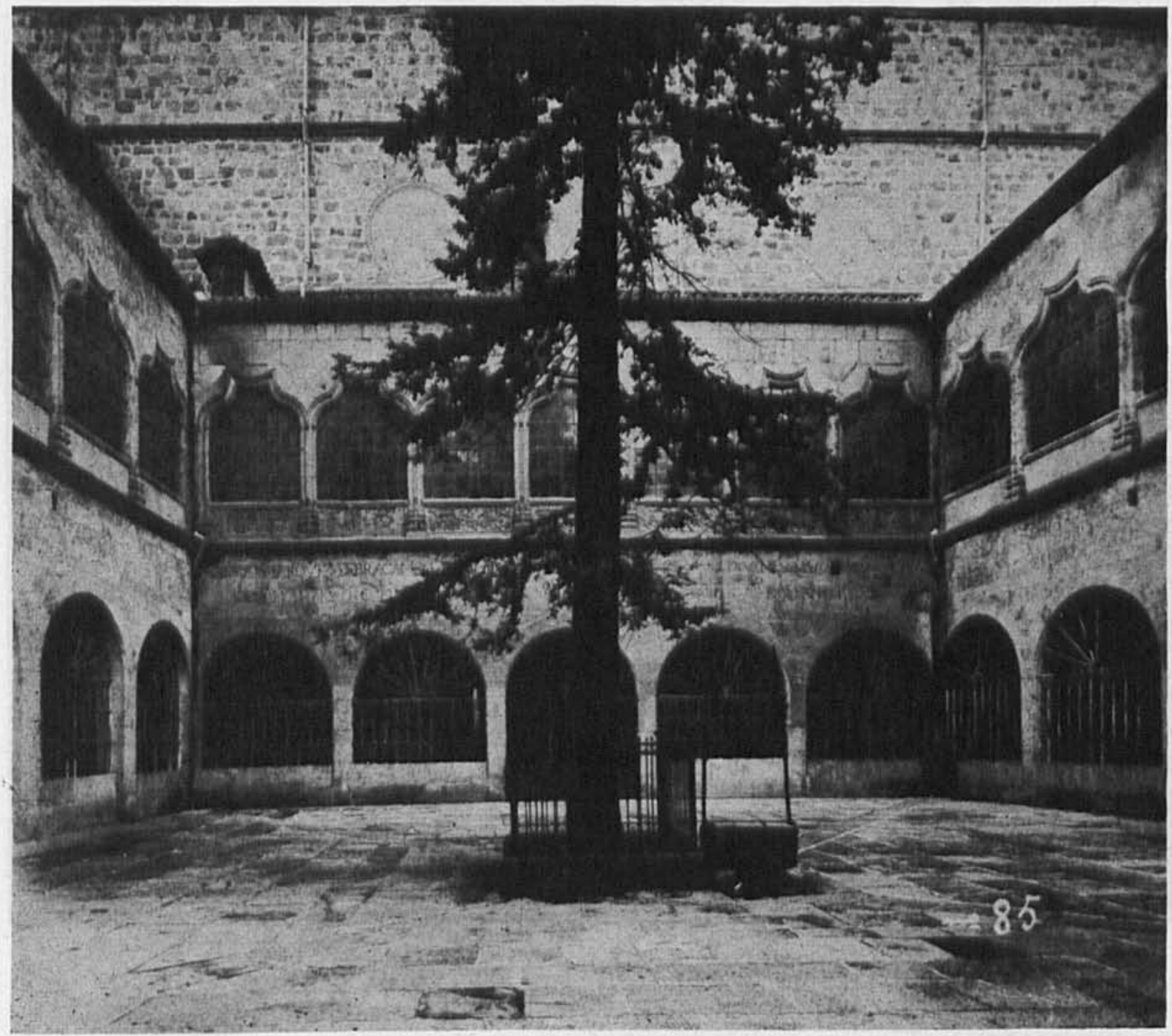

2. Patio de la Universidad 
DOI: http://dx.doi.org/10.22201/iie.18703062e.1974.43.998

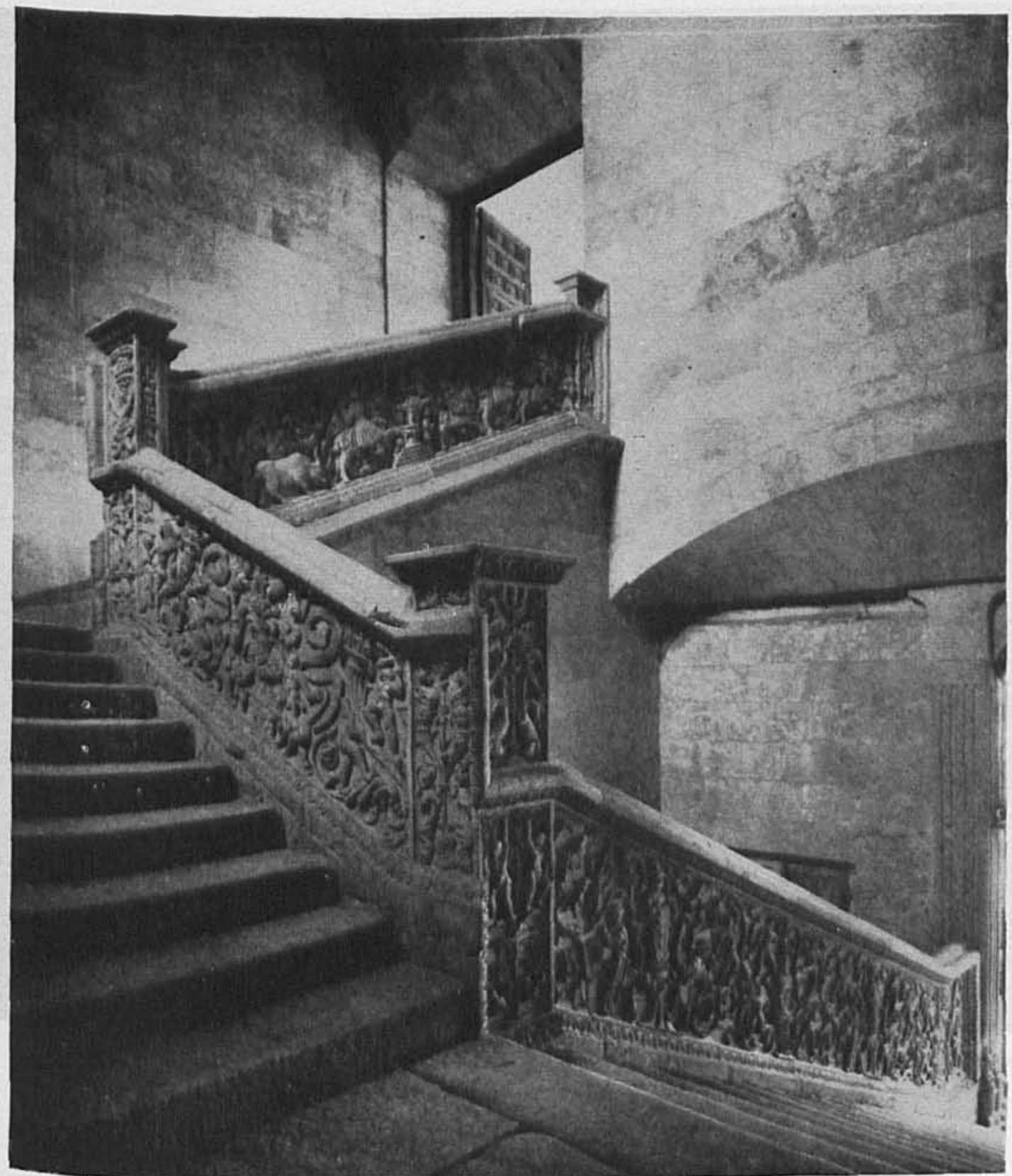

3. Escalera de acceso a la biblioteca 
DOI: http://dx.doi.org/10.22201/iie.18703062e.1974.43.998

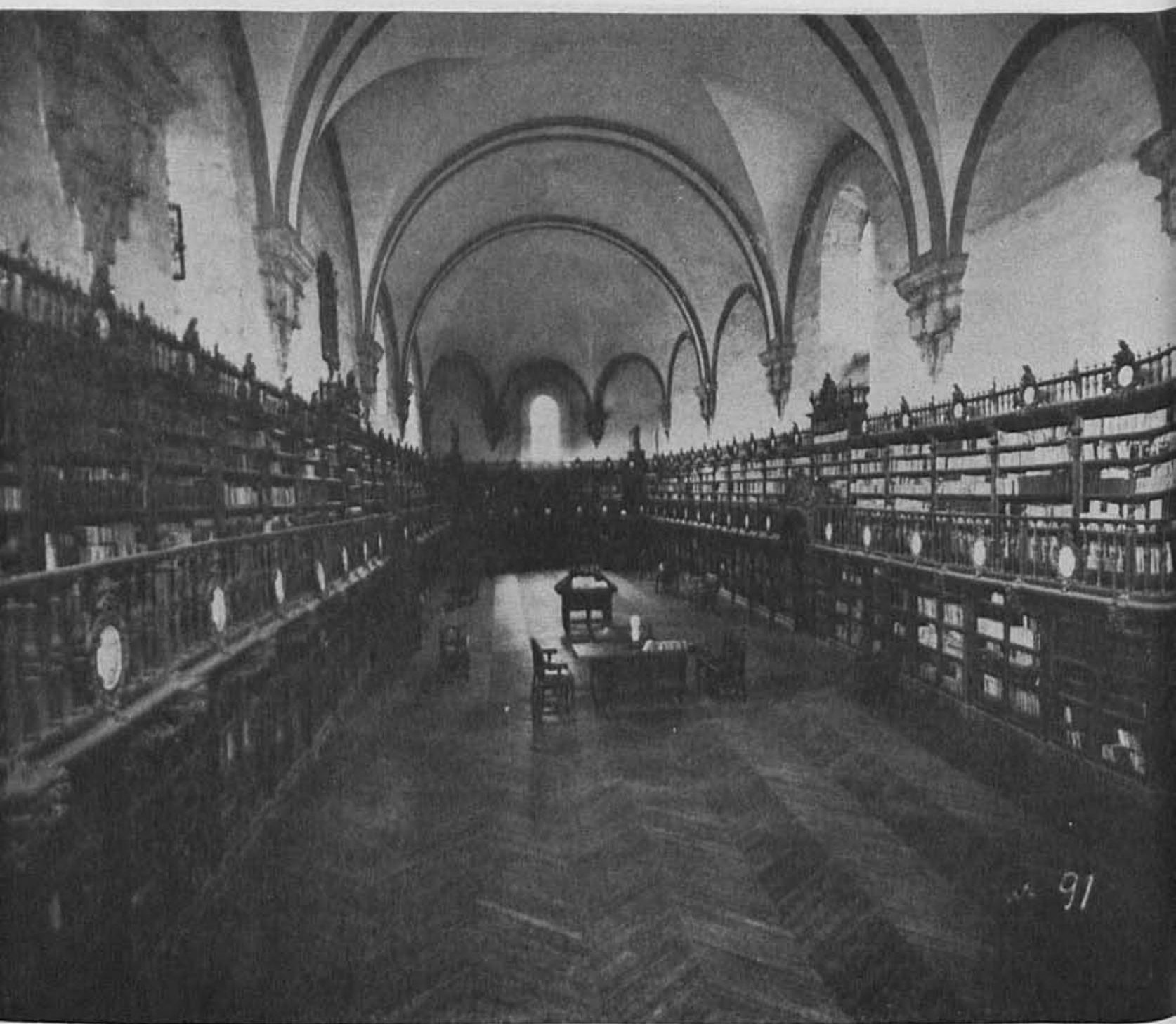

4. Biblioteca 


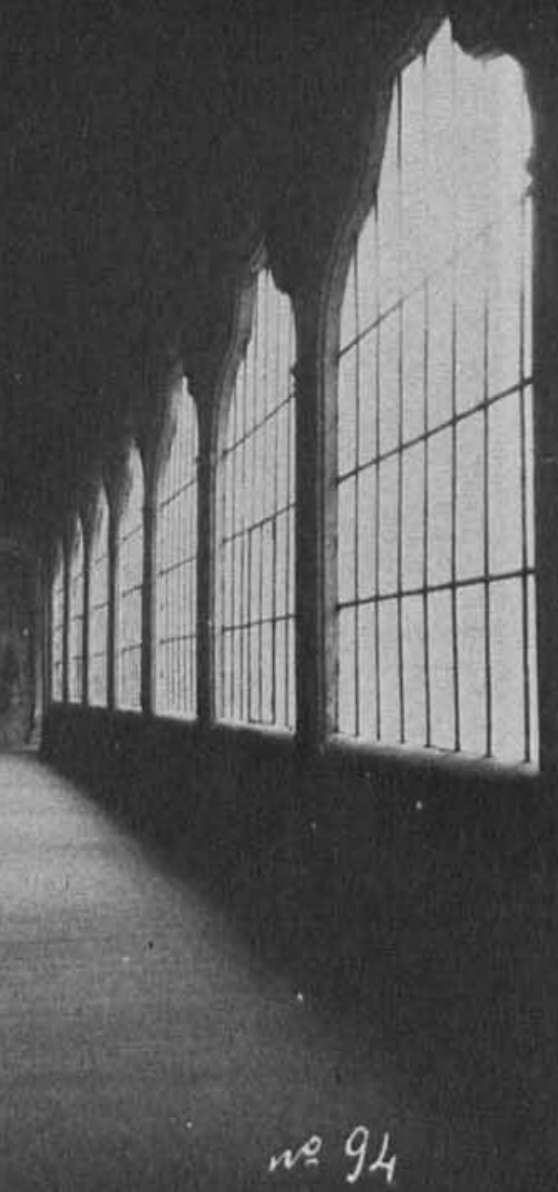

5. Galería alta y puerta de la biblioteca 


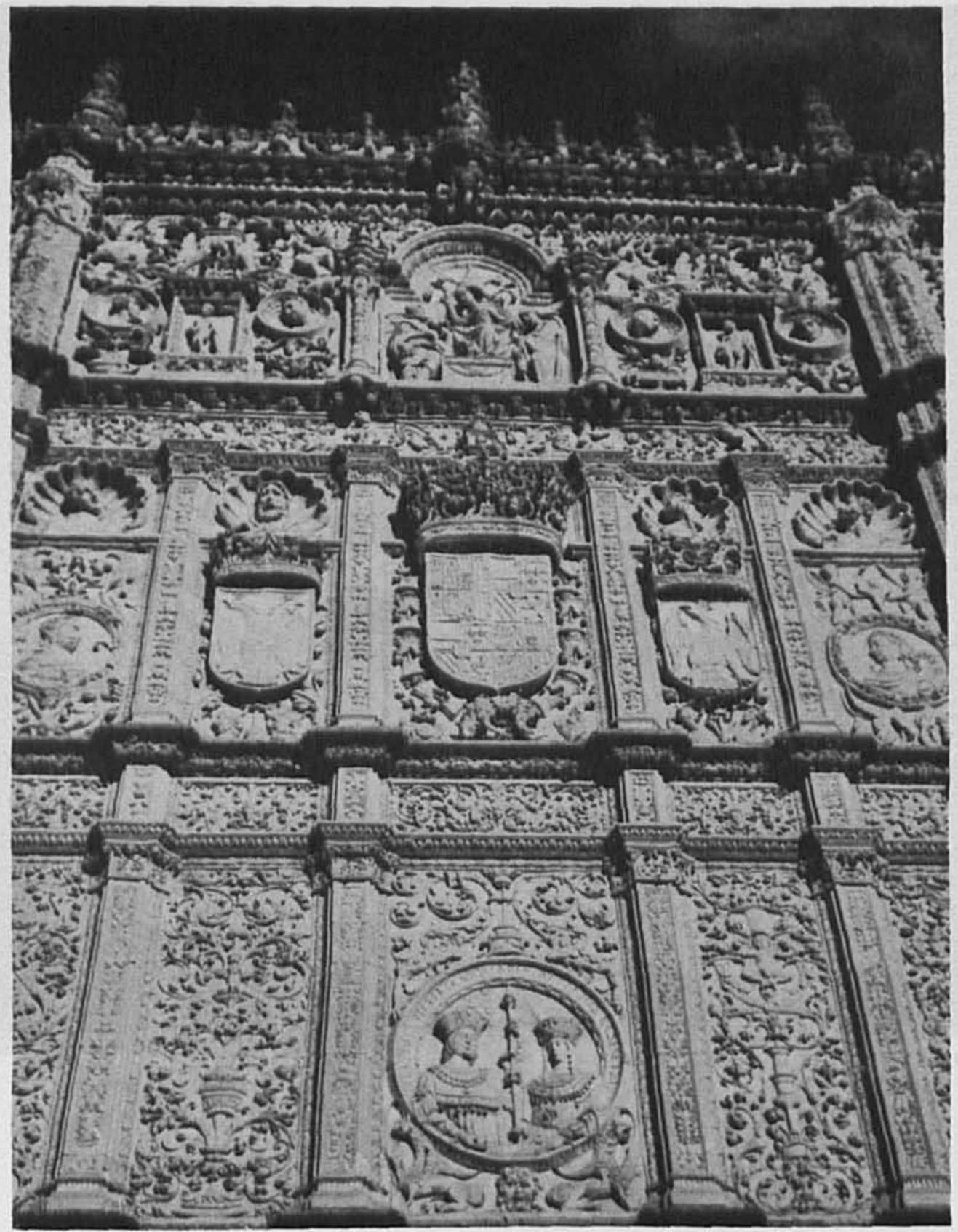

6. Fachada 


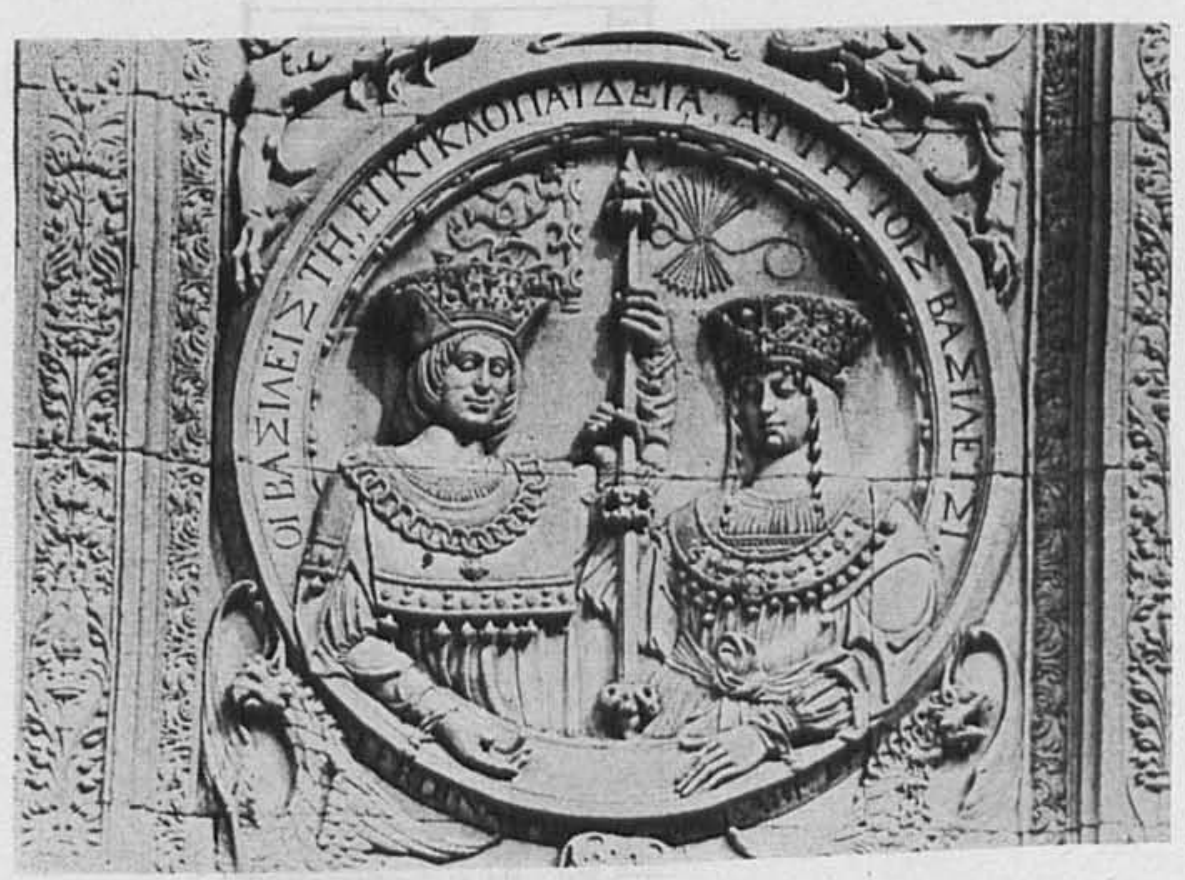

7. Medallón de los Reyes Católicos 
DOI: http://dx.doi.org/10.22201/iie.18703062e.1974.43.998

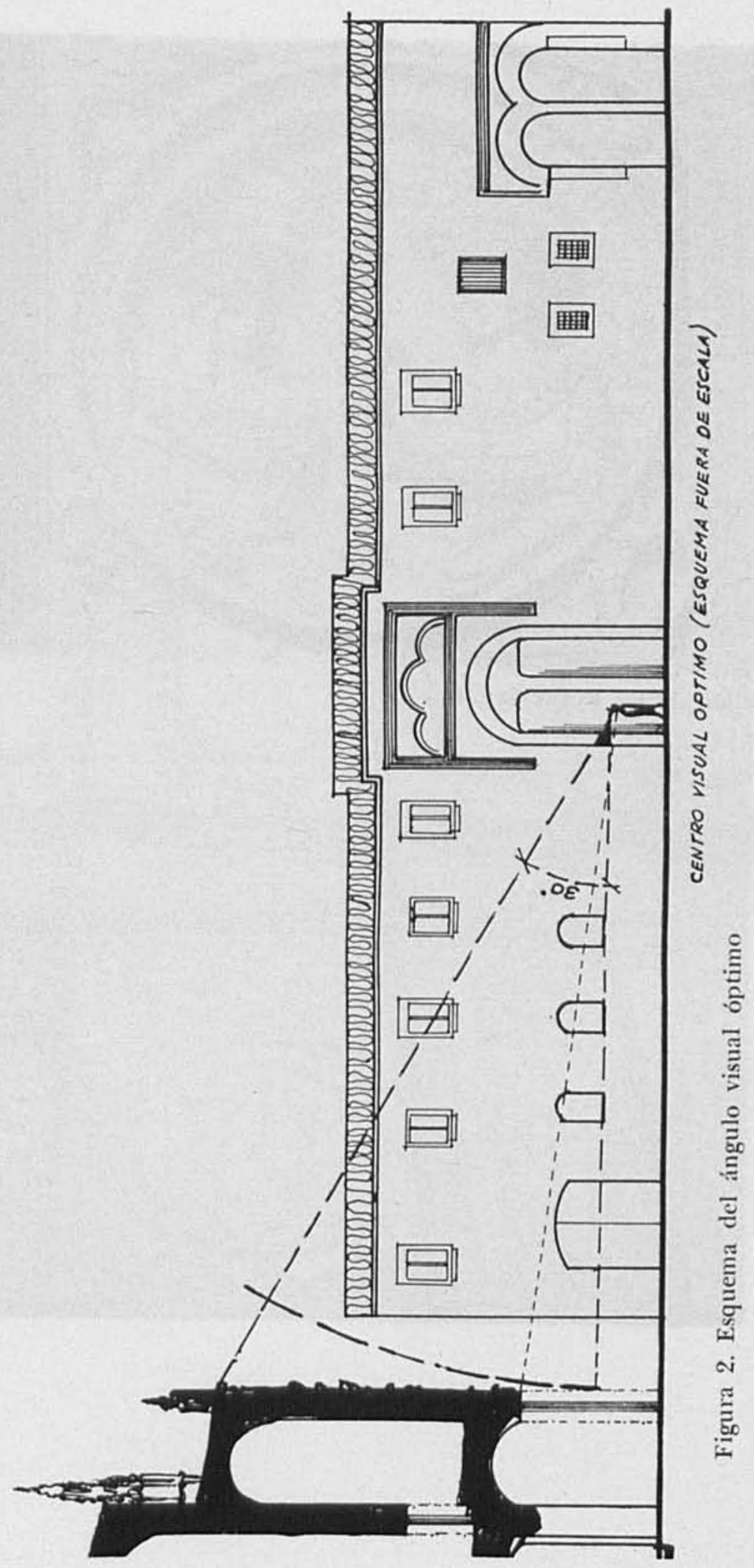


DOI: http://dx.doi.org/10.22201/iie.18703062e.1974.43.998

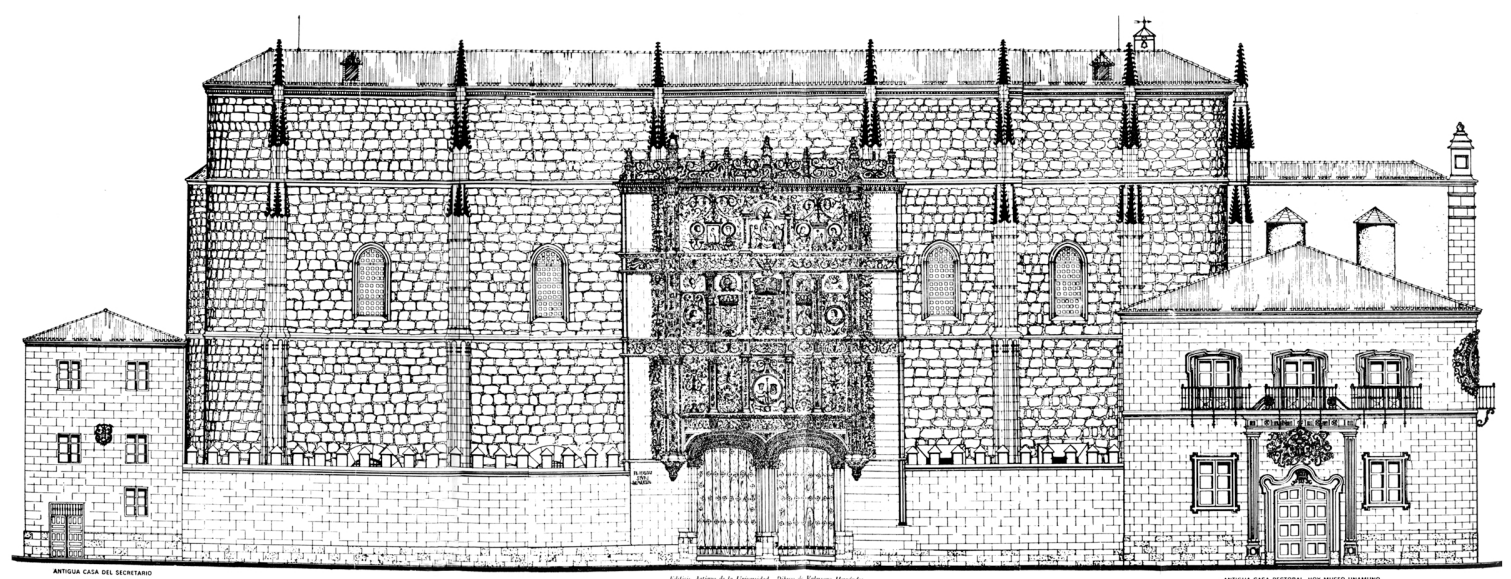




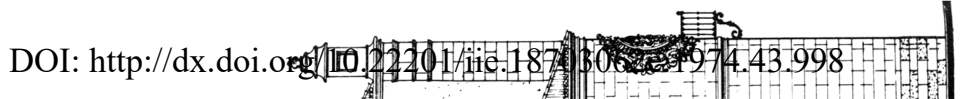

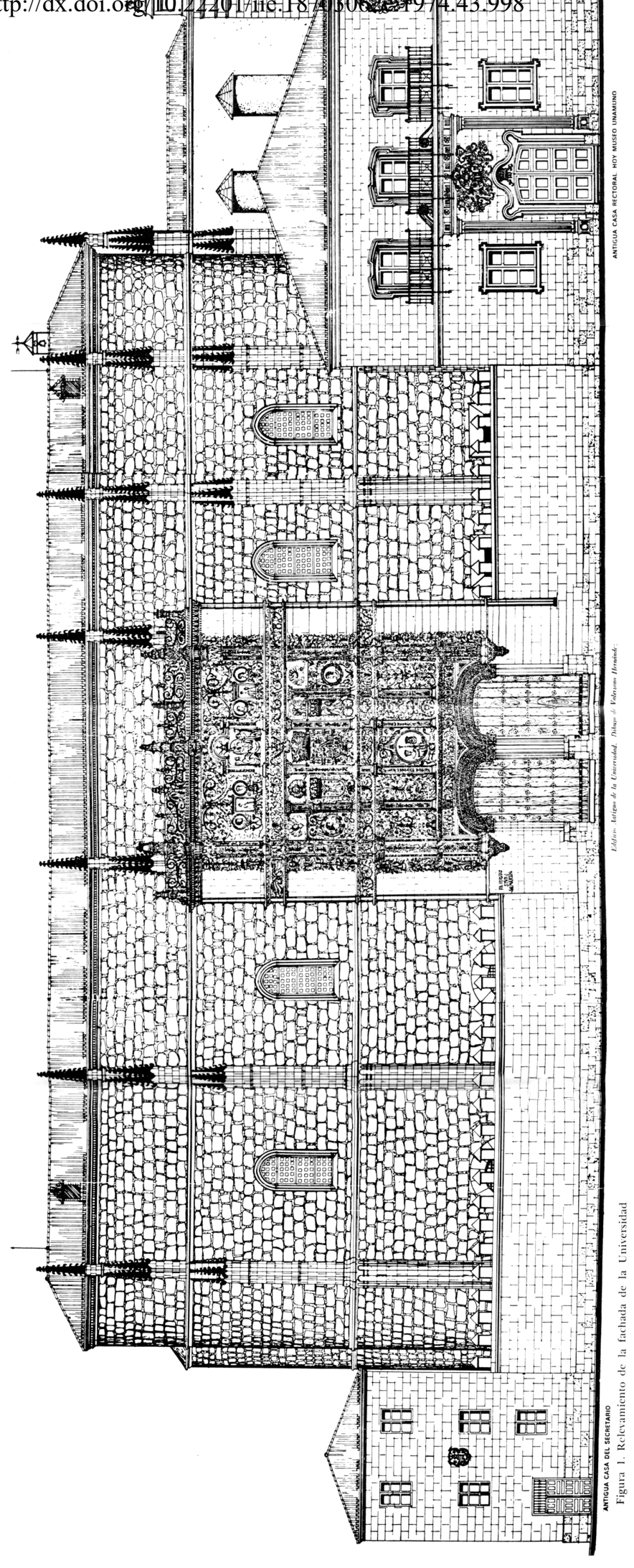


y del patio, en las proximidades del centro de éste. La existencia de este lugar ideal para la contemplación debió estar presente, sin duda, en el ánimo del autor al proyectar la gradación de volúmenes de los ornamentos y la relación de las alturas de las distintas zonas o pisos en que se dividió la fachada. Esto nos revela una vez más la sutileza del autor de la obra y su notable capacidad para conjugar relaciones arquitectónicas, ornamentales y espaciales. Creemos que éstas constituyen razones suficientes para probar que al desprender la fachada del cuerpo del edificio se buscaba lograr la plenitud y complejidad de resultados y efectos que están presentes aunque no sean perceptibles para la mayoría de los espectadores.

Uno de los efectos más extraordinarios que produce esta obra singuIar como resultado de la sabia combinación de relaciones matemáticas, estéticas, visuales y espaciales, y de la existencia del patio, es que el espectador -tenga o no conciencia de ello- se ve forzado a someterse dócil y obediente al imperativo que ejerce. Aun cuando, en general, no cabe duda que el interés de muchos de los espectadores se debe a la riqueza y belleza de la obra (y para algunos simplemente a su popularidad), para satisfacerlo se ven obligados, más bien forzados, a situarse dando frente a la fachada y a la distancia respetuosa que su majestad y señorio exigen; pues la portada de la Universidad es una de las más exigentes, casi tiránicas, que existen y se impone, a la vez, por sus propios méritos y por el espacio que ella requirió, o creó, para ejercer su señorío.

La historia del arte nos ofrece ejemplos de obras plásticas que no fueron hechas para ser vistas, pues con su sola existencia cumplian los fines para los que fueron creadas (como la acción mágica de las pinturas rupestres). Pero la mayorfa de ellas lo han sido para existir visualmente y ser contempladas: de esta manera cumplen su finalidad y satisfacen la razón de su existencia, haciendo que el espectador al participar en la obra de arte contribuya a su existencia. Pero algunas -entre las cuales esta fachada de la Universidad es uno de los ejemplos más extraordinarios- parecen, además, desafiar al espectador; y, provocándole al diálogo o a la polémica, proclaman que existen y existírán a pesar de él; ésta de la Universidad afirma de la manera más rotunda su existencia y parece decirle: "Tú existes en este momento gracias a mi; reclamo que te entregues dócilmente a mi voluntad y hechizo: Colócate de frente, a respetuosa distancia; tu docilidad y obediencia, tu 
sumisión y entrega, son las condiciones necesarias para que seas digno de contemplarme. Tal vez no alcances a ver más que mi tierna epidermis, encendida y ruborosa y algunos rasgos de mi delicada fisonomia; pero para ti, ingenuo espectador, esto bastará para que percibas el palpitar de mis formas y el fluir de la sustancia vital con que el arte y la historia han animado mi existencia".

A diferencia de otras fachadas que toleran la visión oblicua o sesgada y el mirar apresurado, sin detenerse, y de aquellas que exigen el movimiento del espectador frente a ellas, pues su visión no se satisface ni agota plenamente desde ningún punto de vista, como ocurre en las de carácter barroco, ésta de El Estudio Salmantino, no permite ni el apresuramiento ni la visión escorzada y huidiza, y para satisfacer esta exigencia creó el patio, ensanchamiento de la calle, donde ésta se aquieta y remansa, invitando al transeúnte a detenerse un momento $y$, sosegadamente, gozar de la maravillosa belleza de esta espléndida portada de la Universidad Salmantina, desde este patio de las escuelas menores, que siendo escenario, tiene también su propia poesia, su misterio y su hechizo.

\section{Análisis geométrico-estético}

Los principios geométricos y estéticos de las teorías renacentistas, son aplicables a la portada: debiendo advertir, sin embargo, que el carácter de dichos principios y de los métodos de análisis correspondientes originan cierta inseguridad en cuanto a los criterios que pueden aplicarse en este caso.

Las influencias más evidentes proceden de los artistas italianos del siglo xv, especialmente de Alberti, cuya obra como arquitecto y cuyas teorías como tratadista sirvieron de inspiración y orientación a muchos de los artistas de su época y que podemos suponer fueron conocidos por el autor de la portada en cuanto a las relaciones modular y de proporcionalidad de la composición.

Al referirnos a las influencias renacentistas debemos reiterar la distinción entre las de orden decorativo y las estructurales y arquitectónicas. Estas no son estrictamente aplicables a la interpretación de la fachada, pues el concepto de arquitectura no implicada para Alberti relaciones ornamentales sino tectónicas y espaciales, que en este caso, como en tantos otros, fueron quebrantadas y manejadas en España con poco rigor y gran desenvoltura. Los rasgos generales y esenciales de la 
ordenación, las proporciones, equilibrio, armonía, y la subordinación y articulación de las distintas partes a una unidad superior y a una ley modular; reflejan las teorías del arte toscano del siglo xv, que Alberti expuso en su obra $D e$ Re Edificatoria y que resumió en su famosa fórmula sobre la perfección artística que, según él, significa "que a una verdadera obra de arte no se puede quitar ni añadir nada sin destruir su belleza". Fórmula que es aplicable a la portada universitaria, cuya perfección está lograda, a nuestro entender, mediante la estudiada y sabia aplicación de las relaciones y proporciones geométricas o numéricas expuestas por Alberti.

Intentaremos en esta parte poner de manifiesto dichas relaciones aunque repetimos que por su complejidad lo hacemos con cierta inseguridad y algunas reservas.

La primera observación que sugirió el desarrollo de este tema fue el advertir que la superficie de la "portada rica" (desde la imposta de las puertas hasta el alero) es un cuadrado perfecto, figura básica junto con el círculo en las teorías del mencionado autor. Esto motivó la investigación de la ley de relaciones y módulos que a partir de dicha figura simple debió aplicarse en la composición, subdivisiones y ritmos de la portada. ${ }^{21}$

El cuadrado que inscribe el área esencial de la portada, tiene su centro geométrico en el escudo imperial, con lo cual destaca ésta como el centro simbólico y compositivo más relevante de la misma. Podemos suponer que de este cuadrado debieron deducirse las relaciones de las distintas partes en que se subdividió la portada y parece probable que las dimensiones de la parte baja, que corresponde a las puertas, y las de la crestería, se encuentran también en relación proporcional y armónica con dicho cuadrado, el cual serviría de unidad modular. Sin embargo, el tratar de aplicar rigurosamente la lógica y la ciencia de la estética renacentista en las obras españolas resulta casi siempre aventurado, porque los artistas nacionales sólo excepcional y parcialmente aplicaron con fidelidad los principios italianos.

El distinguido arquitecto y profesor de la ENA, señor Martín Larios,

21 Aun cuando nos hemos remitido a Alberti para explicar la fuente de inspiración. debernos recordar que el cuadrado y el circulo fueron considerados desde la antigüedad figuras perfectas dotadas de significados mágicos, religiosos y cósmicos que se conservan durante el Renacimiento y que el afán de cuadratura, como lo señala F. Chueca Goitia en su obra Invariantes castizos de la arquitectura española, está presente en lo musulmán español. 
a quien se deben los adjuntos estudios gráficos y matemáticos, ha llegado provisional o tentativamente a las siguientes conclusiones: "En esta portada existe la relación general $2 / 3$ entre el ancho y el alto". El común denominador es $1 / 6$ de la unidad base, lo que da en el ancho una dimensión modulada de $4 / 6$ y en la altura otra dimensión modulada de 6/3 y, en ambos casos, se mantiene la relación general de 2/3. Estas divisiones establecen la retícula principal de la molduración de la composición total de la fachada.

Se obtiene una progresión 4:6:9, donde el cociente es de 4/9 lo que corresponde a la nota quinta de acuerdo con la teoría musical geomé. trica de Pitágoras.

Los principales elementos simbólicos de la composición se encuen. tran en los puntos 3,5 y 7 de las divisiones modulares de la altura y en el eje principal de simetría de la fachada. Cada elemento está ubica. do con una división modular interna, generándose tres cuadrados: uno de cuatro módulos (cuadrados) en la parte superior y dos (módulos) en la parte inferior, lo que acentúa en posición de "simetria" de acuerdo con el principio vitrubiano que el Renacimiento manejó constantemente.

"El trazo de la fachada universitaria de Salamanca posee cocientes conmensurables que es el rasgo determinante del concepto de proporción empleado por los arquitectos renacentistas. De acuerdo con las ideas principales de Giorgio y Alberti."

Esta breve tentativa hecha para encontrar en la portada el secreto de sus proporciones y con ello uno de los secretos de su belleza, constituye solamente un primer esfuerzo, todavía incompleto e impreciso, por penetrar en la armonía y musicalidad de esta obra excepcional que constituye uno más de los secretos, misterios y enigmas que determinan la indefinible y profunda emoción que produce en el espectador. 